\title{
Trends in Quit Attempts Among Adult Cigarette Smokers - United States, 2001-2013
}

\author{
S. René Lavinghouze, $\mathrm{MA}^{1}$; Ann Malarcher, $\mathrm{PhD}^{1}$; Amal Jama, $\mathrm{MPH}^{2}$; Linda Neff, $\mathrm{PhD}^{1}$; Karen Debrot, $\mathrm{DrPH}^{1}$; Laura Whalen, $\mathrm{MPH}^{1}$
}

During 1965-2012, the prevalence of cigarette smoking among adults (aged $\geq 18$ years) in the United States decreased from $42.4 \%$ to $18.1 \%$, partly because of increases in smoking cessation $(1,2)$. Quitting smoking is beneficial to health at any age, and cigarette smokers who quit before age 35 have premature mortality rates similar to those of persons who never smoked $(1,2)$. To assess progress made toward the Healthy People 2020 target of increasing the proportion of U.S. adult cigarette smokers who made a quit attempt during the past year to $\geq 80 \%$ (objective TU-4.1), ${ }^{*}$ CDC analyzed data from the Behavioral Risk Factor Surveillance System (BRFSS) for the years 2001-2010 and 2011-2013 to provide updated state-specific trends in quit attempts among adult smokers (survey methodology changes required separate analysis of 2011-2013). During 2001-2010, the proportion of smokers who reported a quit attempt during the preceding 12 months increased in 29 states and the U.S. Virgin Islands. During 2011-2013, quit attempts increased in Hawaii and Puerto Rico and decreased in New Mexico. In 2013, past year quit attempts were reported most frequently by smokers in Puerto Rico and Guam (76.4\%) and least frequently by those in Kentucky (56.2\%). In every state, older smokers were generally less likely to report a past year quit attempt than were younger smokers.

Evaluating variation in health risk behaviors and the use of health services is needed to develop interventions and promotion strategies that address public health at multiple levels $(2,3)$. Proven interventions that increase cessation are important for reducing smoking-related morbidity and mortality and include mass media campaigns, telephone-based tobacco cessation services (quitlines), higher prices for tobacco products, comprehensive smoke-free laws, better health insurance coverage of effective cessation treatments, and health systems changes to integrate tobacco dependence treatment into routine clinical

\footnotetext{
*Additional information available at https://www.healthypeople.gov/2020/ topics-objectives/topic/tobacco-use/objectives.
}

care $(1,3)$. The findings in this report support previous findings on variations in quit attempts among states (2) and underscore the continued need for surveillance and evaluation of health risk behaviors to guide preventive health care services (1-3).

The BRFSS is an ongoing, state-based, random-digit-dialed telephone survey of the noninstitutionalized, civilian population aged $\geq 18$ years conducted annually in all 50 states, the District of Columbia (DC), Guam, Puerto Rico, and the U.S. Virgin Islands. ${ }^{\dagger}$ During 2001-2013, BRFSS sample sizes

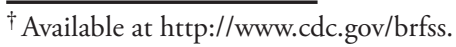

\section{INSIDE}

1136 Cigarette, Cigar, and Marijuana Use Among High School Students — United States, 1997-2013

1142 Use of Surveillance Systems in Detection of a Ciguatera Fish Poisoning Outbreak - Orange County, Florida, 2014

1145 State and Territorial Ebola Screening, Monitoring, and Movement Policy Statements - United States, August 31, 2015

1147 Human Papillomavirus Vaccination Coverage Among School Girls in a Demonstration Project Botswana, 2013

1150 Notes from the Field: A Cluster of Ocular Syphilis Cases - Seattle, Washington, and San Francisco, California, 2014-2015

1152 Announcement

1156 QuickStats

Continuing Education examination available at http://www.cdc.gov/mmwr/cme/conted_info.html\#weekly.

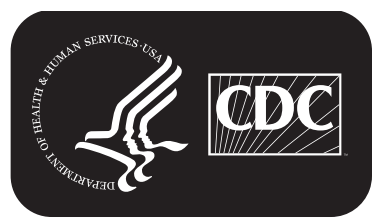


ranged from 212,510 (2001) to 491,773 (2013). Median survey response rates ranged from $44.5 \%$ (2002) to $54.6 \%$ (2010). In 2011, BRFSS added cellular (wireless-only) telephone households to the survey and the sample weighting methodology was updated to accommodate declining response rates and to maintain a representative sample for the U.S. population (4). Because of this change in methodology, data from 2001-2010 and those from 2011-2013 were analyzed separately.

Past year quit attempts of $\geq 1$ day among current smokers (persons who had smoked $\geq 100$ cigarettes during their lifetime and currently smoked "every day" or "some days") were assessed for the years 2001-2010; for the years 2011-2013, past year quit attempts were assessed for both current and former smokers (persons who had smoked $\geq 100$ cigarettes in their lifetime, but did not currently smoke).

The percentage of smokers making quit attempts ${ }^{\S}$ and 95\% confidence intervals were calculated for survey years 2001-2013. For 2001-2010, multivariable logistic regression was used to analyze linear trends in quit attempts for each state, DC, Puerto Rico, and the U.S. Virgin Islands, controlling for sex, age, and race/ethnicity. The Wald chi-square test was used to test for statistical significance $(\mathrm{p}<0.05)$. For 2011-2013, differences in quit attempts were determined from non-overlapping $95 \%$ confidence intervals, because there were too few

\footnotetext{
$\$$ Only current smokers with an unsuccessful quit attempt in the past 12 months were included in calculating quit attempts for 2001-2010; former smokers who had quit in the past year were not included because until 2009, former smokers were not asked when they had last smoked.
}

years to support regression modeling. Quit attempt proportions by age groups were calculated for years 2011-2013 combined. In 2013, approximately two thirds of all adult smokers surveyed reported that they had attempted to quit or did quit in the past year (median $=65.9 \%$ ), with the proportion making a quit attempt ranging from $56.2 \%$ (Kentucky) to $76.4 \%$ (Puerto Rico and Guam) (Table 1). During 2001-2010, there was a significant linear increase in the proportion of adult cigarette smokers who had made a quit attempt in the past year in 29 states and the U.S. Virgin Islands (Figure). The median was $56.1 \%$ in 2001 and $58.8 \%$ in 2010. During 2011-2013, the proportion who had made a quit attempt increased in Hawaii and Puerto Rico and decreased in New Mexico.

During 2011-2013, across all states and DC, the proportion of smokers who reported they had made a quit attempt generally was lower among older respondents (Table 2). The median proportion who had made a quit attempt across states among persons aged 18-24 years, 25-44 years, 45-64 years, and $\geq 65$ years was $73.2 \%, 68.7 \%, 60.9 \%$, and $56.4 \%$, respectively. With the exception of smokers in Montana aged $\geq 65$ years (49.8\%), more than half of smokers, regardless of age group, reported having tried to quit in the past year. Jurisdictions with the highest proportion of respondents reporting having made a quit attempt by age group were DC (18-24 years, 83.5\%), Florida (25-44 years, 74.6\%), and New York (45-64 years, $68.6 \%$, and $\geq 65$ years, $68.0 \%)$. States with the lowest proportion of respondents reporting having made a quit attempt by age group were Maryland (18-24 years, 62.6\%), West Virginia

The MMWR series of publications is published by the Center for Surveillance, Epidemiology, and Laboratory Services, Centers for Disease Control and Prevention (CDC), U.S. Department of Health and Human Services, Atlanta, GA 30329-4027.

Suggested citation: [Author names; first three, then et al., if more than six.] [Report title]. MMWR Morb Mortal Wkly Rep 2015;64:[inclusive page numbers].

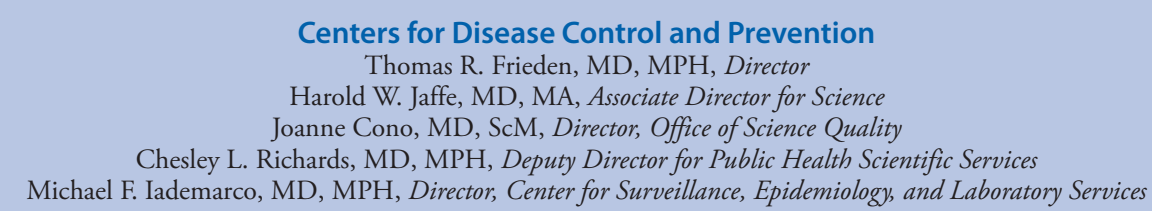

MMWR Editorial and Production Staff (Weekly)

Sonja A. Rasmussen, MD, MS, Editor-in-Chief

Charlotte K. Kent, PhD, MPH, Executive Editor Jacqueline Gindler, MD, Editor

Teresa F. Rutledge, Managing Editor

Douglas W. Weatherwax, Lead Technical Writer-Editor

Soumya Dunworth, PhD, Teresa M. Hood, MS, Jude C. Rutledge, Writer-Editors
Martha F. Boyd, Lead Visual Information Specialist Maureen A. Leahy, Julia C. Martinroe,

Stephen R. Spriggs, Brian E. Wood, Moua Yang, Visual Information Specialists

Quang M. Doan, MBA, Phyllis H. King,

Teresa C. Moreland, Terraye M. Starr, Information Technology Specialists
MMWR Editorial Board

Timothy F. Jones, MD, Chairman

Matthew L. Boulton, MD, MPH Virginia A. Caine, MD

Katherine Lyon Daniel, PhD

Jonathan E. Fielding, MD, MPH, MBA

David W. Fleming, MD
William E. Halperin, MD, DrPH, MPH

King K. Holmes, MD, PhD

Robin Ikeda, MD, MPH

Rima F. Khabbaz, MD

Phyllis Meadows, PhD, MSN, RN

Jewel Mullen, MD, MPH, MPA
Jeff Niederdeppe, $\mathrm{PhD}$

Patricia Quinlisk, MD, MPH

Patrick L. Remington, MD, MPH Carlos Roig, MS, MA

William L. Roper, MD, MPH

William Schaffner, MD 
(25-44 years, $57.1 \%$ ), Nevada and South Dakota (45-64 years, $52.9 \%$ ), and Montana ( $\geq 65$ years, $49.8 \%$ ).

\section{Discussion}

During 2001-2010, the proportion of adult cigarette smokers who had made a quit attempt in the past year increased linearly in 29 states and the U.S. Virgin Islands; during 2011-2013, this proportion increased in Hawaii and Puerto Rico and decreased in New Mexico. During 2011-2013, a majority of smokers in all age groups tried to quit in almost all states, although the proportion of smokers who attempted to quit decreased with increasing age. In 2013, approximately two thirds of smokers had made a quit attempt in the past year, although state proportions ranged from $56.2 \%$ to $76.4 \%$. These results reflect the importance of ongoing state-based surveillance and evaluation in examining state variations and identifying health issues and disparities $(2,3)$. These data can help states to develop health promotion and prevention programs and to monitor their progress in tobacco control.

Helping tobacco users to quit can reduce tobacco-related disease, death, and health care costs $(1,3)$. Increasing taxes on tobacco products, passing and implementing indoor smokefree laws, improving health insurance coverage of cessation services, and integrating tobacco dependence treatment into routine clinical care have all helped increase cessation rates $(1,3)$. State per capita tobacco control program expenditures are one measure of the state's ability to implement effective tobacco control program components, including smoking cessation interventions; in the past decade, states with the highest expenditures have had the greatest declines in cigarette smoking $(1,3,5)$. As part of CDC's National Tobacco Control Program, all states are funded to work toward implementation of comprehensive tobacco control programs that comprise evidencebased strategies to increase smoking cessation, including mass

TABLE 1. Proportion of current cigarette smokers* from 2001-2010 and current and former smokers from 2011-2013 aged $\geq 18$ years who reported a quit attempt in past year, by state and territory — Behavioral Risk Factor Surveillance System, United States, 2001-2013.

\begin{tabular}{|c|c|c|c|c|c|c|c|c|c|c|c|c|c|c|c|c|c|}
\hline \multirow[b]{3}{*}{ State/Territory } & \multirow{2}{*}{\multicolumn{11}{|c|}{ Years 2001-2010 (\%) ${ }^{\dagger}$}} & \multicolumn{6}{|c|}{ Years 2011-2013 $§$} \\
\hline & & & & & & & & & & & & \multicolumn{2}{|r|}{2011} & \multicolumn{2}{|r|}{2012} & \multicolumn{2}{|r|}{2013} \\
\hline & 2001 & 2002 & 2003 & 2004 & 2005 & 2006 & 2007 & 2008 & 2009 & 2010 & $\begin{array}{l}\text { Linear } \\
\text { trend }^{\dagger}\end{array}$ & $\%$ & $(95 \% \mathrm{Cl})$ & $\%$ & $(95 \% \mathrm{Cl})$ & $\%$ & $(95 \% \mathrm{Cl})$ \\
\hline Alabama & 53.4 & 56.3 & 52.3 & 55.3 & 52.4 & 58.9 & 59.4 & 58.0 & 61.7 & 58.1 & $<0.01$ & 62.5 & $(59.2-65.7)$ & 64.5 & $(61.2-67.7)$ & 68.9 & $(65.2-72.5)$ \\
\hline Alaska & 60.8 & 53.9 & 55.2 & 58.1 & 56.7 & 59.0 & 62.3 & 63.5 & 63.2 & 57.8 & 0.10 & 65.5 & $(61.1-69.9)$ & 65.6 & $(61.6-69.7)$ & 65.8 & $(61.9-69.7)$ \\
\hline Arizona & 57.1 & 55.6 & 52.3 & 56.0 & 51.2 & 50.9 & 60.1 & 56.4 & 55.9 & 57.5 & 0.04 & 64.3 & $(59.2-69.4)$ & 66.2 & $(62.1-70.3)$ & 67.3 & $(61.6-72.9)$ \\
\hline Arkansas & 53.2 & 55.3 & 49.0 & 51.5 & 53.3 & 55.1 & 57.1 & 58.2 & 61.6 & 55.8 & $<0.01$ & 64.3 & $(60.0-68.7)$ & 65.5 & $(61.8-69.1)$ & 62.9 & $(59.0-66.8)$ \\
\hline California & 52.9 & 63.3 & 58.3 & 60.1 & 58.8 & 55.7 & 58.1 & 58.4 & 58.6 & 58.1 & 0.92 & 66.9 & $(64.4-69.4)$ & 63.4 & $(60.4-66.3)$ & 67.3 & $(64.1-70.4)$ \\
\hline Colorado & 51.9 & 55.0 & 53.5 & 52.8 & 53.7 & 57.4 & 56.7 & 56.8 & 58.8 & 59.4 & $<0.01$ & 66.9 & $(64.1-69.7)$ & 66.2 & $(63.6-68.8)$ & 64.0 & $(61.3-66.6)$ \\
\hline Connecticut & 56.9 & 61.9 & 56.3 & 56.0 & 54.0 & 55.9 & 58.5 & 62.7 & 59.4 & 61.3 & 0.07 & 68.3 & $(64.5-72.2)$ & 70.6 & $(67.3-73.9)$ & 72.5 & $(69.1-75.8)$ \\
\hline Delaware & 52.7 & 54.6 & 49.7 & 56.7 & 55.6 & 56.1 & 53.4 & 54.5 & 60.5 & 59.9 & $<0.01$ & 67.7 & (63.6-71.8) & 62.6 & (58.4-66.7) & 60.2 & $(55.9-64.6)$ \\
\hline $\begin{array}{l}\text { District of } \\
\text { Columbia }\end{array}$ & 59.6 & 64.3 & 52.0 & 61.9 & 62.3 & 55.5 & 62.4 & 64.2 & 64.5 & 63.6 & 0.09 & 69.5 & $(64.6-74.4)$ & 74.9 & $(69.7-80.1)$ & 74.4 & $(69.6-79.1)$ \\
\hline Florida & 56.0 & 52.0 & 53.1 & 52.0 & 54.2 & 57.3 & 53.2 & 53.4 & 60.3 & 60.1 & $<0.01$ & 68.5 & $(65.7-71.3)$ & 71.9 & $(68.3-75.4)$ & 69.0 & $(66.7-71.4)$ \\
\hline Georgia & 59.2 & 60.1 & 55.2 & 60.4 & 55.8 & 60.7 & 57.4 & 55.4 & 57.6 & 58.8 & 0.52 & 67.6 & (64.6-70.7) & 66.2 & (62.4-69.9) & 65.1 & $(61.7-68.5)$ \\
\hline Hawaii & 59.1 & 49.1 & 58.0 & $* *$ & 63.3 & 61.3 & 61.9 & 57.6 & 58.0 & 60.1 & & 60.8 & $(56.5-65.0)$ & 66.5 & $(62.3-70.6)$ & 70.3 & $(66.5-74.1)$ \\
\hline Idaho & 53.5 & 58.5 & 52.5 & 54.3 & 58.3 & 53.7 & 57.4 & 56.4 & 58.8 & 62.5 & $<0.01$ & 65.0 & $(60.4-69.6)$ & 63.8 & $(58.3-69.4)$ & 68.9 & $(64.8-73.0)$ \\
\hline Illinois & 57.1 & 55.7 & 52.7 & 54.5 & 58.8 & 56.5 & 58.7 & 59.4 & 59.8 & 60.9 & $<0.01$ & 65.5 & $(61.3-69.8)$ & 68.4 & $(64.1-72.6)$ & 64.2 & $(60.1-68.3)$ \\
\hline Indiana & 52.9 & 56.1 & 53.3 & 54.2 & 55.3 & 55.3 & 54.4 & 58.4 & 60.2 & 59.7 & $<0.01$ & 63.0 & $(60.2-65.9)$ & 63.0 & $(60.3-65.7)$ & 63.6 & $(60.9-66.2)$ \\
\hline lowa & 51.4 & 51.9 & 50.5 & 49.4 & 53.0 & 49.1 & 55.7 & 56.3 & 53.2 & 52.5 & 0.02 & 60.6 & (57.4-63.8) & 64.1 & $(60.9-67.3)$ & 59.8 & $(56.5-63.2)$ \\
\hline Kansas & 50.8 & 50.8 & 45.8 & 48.9 & 51.1 & 56.2 & 54.9 & 53.8 & 54.0 & 56.8 & $<0.01$ & 61.1 & $(59.2-63.1)$ & 63.1 & $(60.5-65.7)$ & 63.6 & $(61.9-65.4)$ \\
\hline Kentucky & 47.7 & 48.2 & 49.3 & 52.2 & 50.7 & 48.3 & 49.5 & 55.5 & 58.0 & 56.3 & $<0.01$ & 58.2 & $(55.3-61.1)$ & 59.6 & $(56.7-62.4)$ & 56.2 & $(53.3-59.1)$ \\
\hline Louisiana & 56.6 & 58.6 & 54.2 & 59.9 & 62.5 & 57.1 & 54.8 & 57.1 & 60.9 & 60.1 & 0.33 & 65.1 & $(62.2-68.0)$ & 64.4 & $(61.0-67.8)$ & 65.9 & $(61.3-70.5)$ \\
\hline Maine & 60.3 & 61.1 & 54.1 & 59.3 & 54.3 & 59.7 & 57.9 & 57.2 & 60.1 & 58.7 & 0.60 & 64.4 & (61.8-66.9) & 66.6 & $(63.9-69.2)$ & 64.0 & $(60.7-67.3)$ \\
\hline Maryland & 56.4 & 57.8 & 53.2 & 56.0 & 54.5 & 59.8 & 62.3 & 60.0 & 59.1 & 57.7 & 0.12 & 61.7 & $(58.0-65.4)$ & 66.8 & (63.4-70.3) & 67.6 & $(64.4-70.7)$ \\
\hline Massachusetts & 56.7 & 60.5 & 56.1 & 58.0 & 58.2 & 58.1 & 59.7 & 59.8 & 61.2 & 63.1 & $<0.01$ & 67.2 & (64.7-69.7) & 67.6 & $(65.2-70.0)$ & 67.5 & $(64.6-70.4)$ \\
\hline Michigan & 58.5 & 59.7 & 61.2 & 61.9 & 61.3 & 62.3 & 61.1 & 57.7 & 61.4 & 62.4 & 0.10 & 65.6 & $(62.7-68.6)$ & 68.5 & $(65.7-71.2)$ & 68.0 & $(65.5-70.4)$ \\
\hline Minnesota & 59.6 & 56.8 & 54.7 & 49.2 & 57.3 & 59.3 & 58.1 & 56.9 & 56.6 & 57.2 & 0.17 & 64.3 & (61.7-66.8) & 64.4 & $(61.9-67.0)$ & 68.3 & $(65.2-71.4)$ \\
\hline Mississippi & 56.2 & 57.9 & 58.1 & 55.4 & 57.5 & 62.1 & 56.8 & 55.8 & 59.6 & 63.9 & 0.02 & 64.9 & $(62.0-67.8)$ & 66.0 & $(62.8-69.3)$ & 69.4 & $(66.2-72.6)$ \\
\hline Missouri & 54.1 & 48.8 & 47.9 & 49.9 & 52.2 & 52.1 & 55.2 & 54.0 & 54.4 & 51.9 & 0.09 & 58.6 & $(55.2-62.1)$ & 60.9 & $(57.5-64.4)$ & 63.8 & $(60.3-67.3)$ \\
\hline Montana & 48.1 & 51.6 & 52.1 & 52.3 & 53.9 & 59.7 & 60.5 & 56.1 & 58.5 & 57.0 & $<0.01$ & 58.2 & $(55.1-61.3)$ & 61.4 & $(58.4-64.5)$ & 60.9 & (57.9-63.8) \\
\hline Nebraska & 51.2 & 56.9 & 53.5 & 54.8 & 51.8 & 54.7 & 50.1 & 53.7 & 54.5 & 58.8 & 0.28 & 62.0 & $(60.1-63.9)$ & 63.0 & $(60.8-65.2)$ & 64.0 & $(61.3-66.8)$ \\
\hline Nevada & 50.6 & 53.9 & 46.9 & 49.4 & 57.9 & 56.3 & 56.3 & 55.2 & 53.5 & 55.1 & 0.40 & 58.6 & $(54.0-63.1)$ & 66.7 & $(62.6-70.7)$ & 62.5 & $(57.1-67.8)$ \\
\hline New Hampshire & 58.7 & 60.4 & 52.3 & 59.8 & 57.3 & 58.2 & 59.1 & 61.5 & 63.8 & 59.9 & 0.01 & 61.7 & $(57.8-65.6)$ & 66.0 & $(61.9-70.0)$ & 66.8 & $(63.1-70.5)$ \\
\hline New Jersey & 58.2 & 60.1 & 55.9 & 57.9 & 59.0 & 60.2 & 64.2 & 59.3 & 60.7 & 58.5 & 0.09 & 68.7 & $(66.1-71.3)$ & 69.6 & $(67.1-72.2)$ & 71.0 & $(68.3-73.7)$ \\
\hline New Mexico & 55.5 & 56.5 & 51.3 & 54.6 & 56.8 & 59.0 & 57.4 & 58.4 & 59.6 & 62.2 & $<0.01$ & 69.6 & $(66.8-72.4)$ & 63.8 & $(60.9-66.7)$ & 63.3 & $(60.1-66.4)$ \\
\hline New York & 57.2 & 62.4 & 56.7 & 59.8 & 60.5 & 59.2 & 63.1 & 64.2 & 66.7 & 63.6 & $<0.01$ & 71.7 & $(68.6-74.8)$ & 73.0 & $(69.6-76.5)$ & 70.5 & (67.4-73.6) \\
\hline North Carolina & 55.6 & 57.9 & 52.6 & 55.8 & 54.9 & 57.3 & 56.9 & 58.4 & 59.4 & 60.6 & 0.13 & 66.9 & (63.9-69.9) & 68.5 & $(66.1-70.8)$ & 65.1 & $(62.2-68.1)$ \\
\hline North Dakota & 57.8 & 52.7 & 51.8 & 51.5 & 51.2 & 49.1 & 52.8 & 52.3 & 54.9 & 58.6 & 0.68 & 59.5 & $(55.6-63.4)$ & 59.3 & $(55.1-63.4)$ & 58.7 & $(55.1-62.2)$ \\
\hline
\end{tabular}

See table footnotes on the next page. 
TABLE 1. (Continued) Proportion of current cigarette smokers* from 2001-2010 and current and former smokers from 2011-2013 aged $\geq 18$ years who reported a quit attempt in past year, by state and territory - Behavioral Risk Factor Surveillance System, United States, $2001-2013$.

\begin{tabular}{|c|c|c|c|c|c|c|c|c|c|c|c|c|c|c|c|c|c|}
\hline \multirow[b]{3}{*}{ State/Territory } & \multirow{2}{*}{\multicolumn{11}{|c|}{ Years 2001-2010 (\%) ${ }^{\dagger}$}} & \multicolumn{6}{|c|}{ Years 2011-2013 $\S$} \\
\hline & & & & & & & & & & & & \multicolumn{2}{|r|}{2011} & \multicolumn{2}{|r|}{2012} & \multicolumn{2}{|r|}{2013} \\
\hline & 2001 & 2002 & 2003 & 2004 & 2005 & 2006 & 2007 & 2008 & 2009 & 2010 & $\begin{array}{l}\text { Linear } \\
\text { trend }^{\dagger}\end{array}$ & $\%$ & $(95 \% \mathrm{Cl})$ & $\%$ & $(95 \% \mathrm{Cl})$ & $\%$ & $(95 \% \mathrm{Cl})$ \\
\hline Ohio & 50.6 & 51.9 & 50.0 & 47.8 & 52.7 & 57.0 & 55.9 & 56.7 & 59.1 & 55.2 & $<0.01$ & 61.2 & $(58.3-64.0)$ & 61.9 & $(59.5-64.4)$ & 65.9 & $(63.3-68.4)$ \\
\hline Oklahoma & 52.3 & 51.9 & 49.3 & 52.1 & 51.6 & 57.3 & 57.4 & 57.6 & 58.8 & 58.4 & $<0.01$ & 62.8 & $(59.9-65.8)$ & 66.4 & $(63.6-69.2)$ & 64.9 & $(62.1-67.7)$ \\
\hline Oregon & 59.9 & 55.2 & 52.4 & 50.4 & 54.0 & 52.5 & 58.4 & 53.6 & 55.0 & 53.9 & 0.58 & 65.4 & $(61.8-69.0)$ & 69.9 & $(66.1-73.7)$ & 65.1 & $(61.3-69.0)$ \\
\hline Pennsylvania & 53.6 & 54.8 & 52.5 & 53.9 & 55.9 & 57.7 & 57.5 & 60.6 & 57.0 & 54.7 & $<0.01$ & 65.8 & $(63.3-68.3)$ & 66.2 & $(63.9-68.4)$ & 66.7 & $(64.2-69.1)$ \\
\hline Rhode Island & 61.5 & 65.7 & 56.3 & 59.3 & 59.0 & 60.5 & 57.9 & 66.7 & 62.8 & 64.0 & 0.29 & 68.2 & (64.6-71.7) & 65.4 & $(61.3-69.5)$ & 69.5 & $(65.8-73.2)$ \\
\hline South Carolina & 57.9 & 56.3 & 55.4 & 56.9 & 55.4 & 57.1 & 58.9 & 57.9 & 58.8 & 65.4 & $<0.01$ & 65.0 & $(62.1-67.8)$ & 68.5 & $(66.0-71.1)$ & 67.4 & $(64.7-70.1)$ \\
\hline South Dakota & 55.2 & 57.6 & 57.3 & 54.0 & 53.3 & 56.8 & 57.4 & 57.9 & 56.8 & 59.4 & 0.12 & 63.6 & $(59.3-68.0)$ & 60.5 & $(57.1-64.0)$ & 63.1 & (59.1-67.2) \\
\hline Tennessee & 57.2 & 52.7 & 51.3 & 51.4 & 55.5 & 58.6 & 56.9 & 61.2 & 57.2 & 60.8 & $<0.01$ & 66.2 & $(61.0-71.4)$ & 66.7 & $(63.5-69.8)$ & 66.8 & $(63.3-70.4)$ \\
\hline Texas & 58.2 & 53.9 & 51.9 & 54.1 & 54.7 & 58.2 & 58.0 & 59.6 & 62.8 & 60.7 & $<0.01$ & 69.4 & $(66.5-72.2)$ & 67.3 & $(64.2-70.4)$ & 69.9 & $(67.0-72.9)$ \\
\hline Utah & 65.7 & 68.5 & 58.1 & 59.7 & 59.9 & 58.5 & 62.3 & 61.5 & 59.7 & 64.8 & 0.33 & 70.0 & $(66.8-73.2)$ & 71.7 & $(68.5-74.9)$ & 69.5 & $(66.5-72.6)$ \\
\hline Vermont & 55.5 & 55.3 & 50.5 & 59.7 & 54.6 & 55.2 & 57.3 & 58.2 & 59.0 & 62.9 & $<0.01$ & 62.8 & (59.0-66.6) & 69.3 & $(65.6-73.0)$ & 63.9 & $(60.1-67.6)$ \\
\hline Virginia & 52.0 & 55.2 & 52.5 & 54.1 & 56.0 & 57.6 & 55.4 & 60.1 & 60.6 & 51.9 & $<0.01$ & 63.9 & $(60.2-67.7)$ & 65.4 & $(62.1-68.8)$ & 65.8 & $(62.8-68.8)$ \\
\hline Washington & 63.8 & 57.2 & 55.1 & 57.8 & 54.1 & 59.2 & 58.0 & 55.9 & 57.0 & 58.4 & 0.35 & 64.8 & $(61.4-68.1)$ & 65.8 & $(63.3-68.4)$ & 67.5 & $(64.7-70.3)$ \\
\hline West Virginia & 53.0 & 48.4 & 49.9 & 51.9 & 49.9 & 53.5 & 55.5 & 59.0 & 55.9 & 53.5 & 0.01 & 57.4 & $(54.2-60.7)$ & 56.1 & $(53.0-59.1)$ & 59.7 & $(56.8-62.7)$ \\
\hline Wisconsin & 56.1 & 57.4 & 49.4 & 53.2 & 49.5 & 58.3 & 57.6 & 59.4 & 62.5 & 62.1 & $<0.01$ & 67.3 & $(63.2-71.4)$ & 68.4 & $(64.4-72.4)$ & 71.3 & $(67.5-75.1)$ \\
\hline Wyoming & 49.7 & 57.9 & 52.1 & 53.0 & 57.0 & 58.8 & 56.6 & 54.7 & 56.4 & 58.2 & 0.03 & 61.5 & $(58.0-64.9)$ & 61.6 & $(57.0-66.3)$ & 62.7 & $(58.8-66.6)$ \\
\hline Median & 56.1 & 56.3 & 52.5 & 54.6 & 55.3 & 57.3 & 57.4 & 57.9 & 59.1 & 58.8 & & 64.9 & & 66.0 & & 65.9 & \\
\hline Guam & 61.6 & 66.8 & 61.3 & ๆ & १ & 9 & 64.7 & 66.4 & 58.3 & 69.1 & ก & $* *$ & $* *$ & 72.0 & $(67.0-77.0)$ & 76.4 & $(71.6-81.2)$ \\
\hline $\begin{array}{l}\text { Puerto Rico, } \\
\text { Commonwealth }\end{array}$ & 71.8 & 66.5 & 60.5 & 61.2 & 64.6 & 68.0 & 65.1 & 66.7 & 73.5 & 64.2 & 0.41 & 66.0 & $(62.0-70.0)$ & 70.5 & $(66.5-74.4)$ & 76.4 & $(72.1-80.8)$ \\
\hline U.S. Virgin Islands & 54.0 & 56.8 & 59.3 & 60.9 & 64.3 & 62.5 & 57.7 & 59.7 & 66.1 & 65.1 & 0.02 & १ & q & १ & ๆ & $\pi$ & १ \\
\hline
\end{tabular}

Abbreviation: $\mathrm{Cl}=$ confidence interval.

* For years 2001-2010 quit attempt proportions were calculated among current cigarette smokers aged $\geq 18$ years who reported having stopped smoking for $\geq 1$ day during the past 12 months. Data were weighted to representative of the state and territory population.

+ Linear trend test $p$-value. For years 2001-2010 linear trends for the relationship between time and quit attempt prevalence were assessed using orthogonal polynomials in logistic regression models controlling for sex, age, and race/ethnicity. Trends were not analyzed if data were missing for multiple years.

$\S$ For years 2011-2013 quit attempt proportions and 95\% Cls were calculated among both current and former cigarette smokers aged $\geq 18$ years who during the past 12 months reported having stopped smoking for 1 day or longer.

" Behavioral Risk Factor Surveillance System data were not collected during these years.

** The sample size for Guam in 2011 was $<50$.

FIGURE. Trends in the proportion of adult smokers reporting a quit attempt during the previous year, by state - Behavioral Risk Factor Surveillance System, United States, 2001-2010

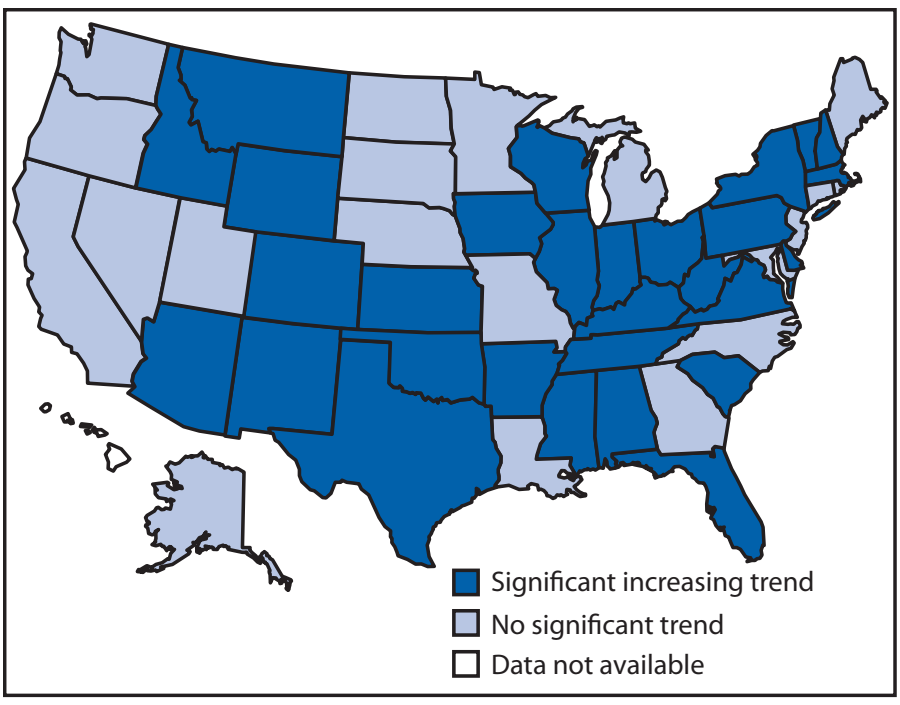

media campaigns with graphic anti-smoking ads, such as the Tips from Former Smokers (Tips) campaign. Tips profiles former smokers who are living with serious long-term health effects from smoking and secondhand smoke exposure, and refers smokers who want help quitting to the national toll-free portal number, 1-800-QUIT-NOW. During the first phase of the campaign (March 19-June 10, 2012), calls to the quitline increased and resulted in an additional 1.6 million smokers making a quit attempt $(1,6)$.

Variations by states in the proportion of cigarette smokers who reported having made a quit attempt in the past year might be attributed to a number of factors, including differences in population demographics; tobacco control program infrastructure, programs, and policies; and awareness, availability, accessibility, and use of smoking cessation treatments $(1,3,7)$. Nationally, younger persons, African Americans, and

\footnotetext{
Additional information available at http://www.cdc.gov/tobacco/campaign/tips.
} 
TABLE 2. Proportion of current and former cigarette smokers* aged $\geq 18$ years who reported a quit attempt in the past year by state and territory and age group, Behavioral Risk Factor Surveillance System — United States, 2011-2013.

\begin{tabular}{|c|c|c|c|c|c|c|c|c|}
\hline \multirow[b]{3}{*}{ State/Territory } & \multicolumn{8}{|c|}{ Age group (yrs) } \\
\hline & \multicolumn{2}{|c|}{$18-24$} & \multicolumn{2}{|c|}{$25-44$} & \multicolumn{2}{|c|}{$45-64$} & \multicolumn{2}{|c|}{$\geq 65$} \\
\hline & $\%$ & $95 \% \mathrm{Cl}$ & $\%$ & $95 \% \mathrm{Cl}$ & $\%$ & $95 \% \mathrm{Cl}$ & $\%$ & $95 \% \mathrm{Cl}$ \\
\hline Alabama & 72.0 & $(65.5-78.4)$ & 66.8 & $(63.5-70.2)$ & 62.3 & $(51.0-60.6)$ & 56.4 & $(51.9-60.9)$ \\
\hline Alaska & 78.2 & (72.5-83.8) & 66.3 & $(62.4-70.2)$ & 61.4 & $(43.4-57.8)$ & 54.9 & $(47.1-62.6)$ \\
\hline Arizona & 71.8 & $(63.3-80.4)$ & 68.6 & $(63.6-73.6)$ & 62.6 & $(50.7-63.2)$ & 57.5 & $(51.5-63.5)$ \\
\hline Arkansas & 70.7 & $(62.9-78.4)$ & 68.1 & $(64.2-72.0)$ & 59.4 & $(52.5-63.4)$ & 55.5 & $(50.6-60.5)$ \\
\hline California & 72.7 & (68.1-77.4) & 69.7 & $(67.2-72.3)$ & 60.8 & $(45.3-55.4)$ & 54.3 & $(49.5-59.0)$ \\
\hline Colorado & 71.8 & $(67.0-76.6)$ & 70.8 & $(68.4-73.1)$ & 58.8 & $(49.0-57.9)$ & 53.5 & $(49.5-57.5)$ \\
\hline Connecticut & 75.2 & $(67.8-82.6)$ & 72.8 & $(69.5-76.1)$ & 68.4 & $(57.6-68.7)$ & 60.8 & $(55.8-65.7)$ \\
\hline Delaware & 72.1 & $(65.2-79.0)$ & 65.5 & $(61.3-69.7)$ & 59.0 & $(45.9-59.5)$ & 60.6 & $(55.1-66.1)$ \\
\hline District of Columbia & 83.5 & $(74.8-92.2)$ & 74.0 & $(69.4-78.6)$ & 68.4 & $(58.4-76.0)$ & 67.9 & $(61.4-74.5)$ \\
\hline Florida & 78.3 & $(73.0-83.7)$ & 74.6 & $(71.8-77.4)$ & 63.9 & $(51.3-64.1)$ & 63.2 & $(58.9-67.4)$ \\
\hline Georgia & 74.5 & $(68.7-80.3)$ & 68.6 & $(65.3-71.8)$ & 60.9 & $(48.4-60.5)$ & 61.6 & $(56.6-66.5)$ \\
\hline Hawaii & 74.2 & $(67.0-81.5)$ & 68.7 & $(65.2-72.1)$ & 59.5 & $(50.8-67.7)$ & 55.5 & $(48.6-62.5)$ \\
\hline Idaho & 76.7 & $(69.2-84.1)$ & 66.8 & (62.3-71.4) & 61.7 & $(47.6-63.9)$ & 56.3 & $(50.3-62.3)$ \\
\hline Illinois & 72.8 & $(65.9-79.8)$ & 70.6 & $(66.6-74.7)$ & 59.8 & $(49.1-62.4)$ & 55.8 & $(49.8-61.9)$ \\
\hline Indiana & 72.6 & $(67.3-77.8)$ & 66.2 & $(63.7-68.8)$ & 57.3 & $(46.2-54.8)$ & 56.3 & $(52.5-60.1)$ \\
\hline lowa & 70.5 & $(64.8-76.1)$ & 64.8 & $(61.7-67.9)$ & 54.7 & $(47.3-57.4)$ & 55.4 & $(50.8-60.0)$ \\
\hline Kansas & 72.2 & $(68.5-76.0)$ & 65.3 & $(63.3-67.3)$ & 57.5 & $(50.3-58.5)$ & 50.8 & $(48.0-53.7)$ \\
\hline Kentucky & 65.1 & (59.8-70.4) & 59.7 & $(57.0-62.4)$ & 54.4 & $(47.8-56.6)$ & 52.0 & $(47.7-56.3)$ \\
\hline Louisiana & 77.6 & $(70.6-84.5)$ & 65.1 & $(61.5-68.6)$ & 61.8 & $(54.2-64.5)$ & 60.4 & $(55.8-65.0)$ \\
\hline Maine & 72.1 & $(67.1-77.1)$ & 66.3 & $(63.6-69.0)$ & 61.6 & $(50.7-59.5)$ & 59.4 & $(55.2-63.6)$ \\
\hline Maryland & 62.6 & $(54.9-70.3)$ & 70.4 & (67.1-73.7) & 62.2 & $(52.6-62.5)$ & 58.1 & $(53.1-63.2)$ \\
\hline Massachusetts & 71.4 & $(66.7-76.1)$ & 69.4 & $(66.9-71.9)$ & 64.6 & $(55.3-63.0)$ & 62.1 & (58.3-65.9) \\
\hline Michigan & 73.4 & $(68.6-78.2)$ & 69.3 & (66.7-72.0) & 64.6 & $(57.6-66.1)$ & 59.2 & $(55.0-63.4)$ \\
\hline Minnesota & 71.4 & $(66.9-75.9)$ & 69.7 & $(67.4-72.1)$ & 60.9 & $(49.8-58.6)$ & 53.7 & $(48.6-58.9)$ \\
\hline Mississippi & 75.2 & $(69.8-80.6)$ & 69.2 & $(66.2-72.2)$ & 61.4 & $(52.5-62.1)$ & 62.7 & $(58.6-66.8)$ \\
\hline Missouri & 73.2 & $(67.2-79.2)$ & 62.7 & $(59.4-66.1)$ & 56.1 & $(43.3-53.7)$ & 53.4 & $(48.3-58.5)$ \\
\hline Montana & 67.4 & $(62.2-72.6)$ & 65.3 & $(62.4-68.2)$ & 54.4 & $(45.9-55.4)$ & 49.8 & $(45.4-54.1)$ \\
\hline Nebraska & 74.4 & (70.8-77.9) & 66.3 & $(64.2-68.4)$ & 56.0 & $(47.7-55.1)$ & 52.5 & $(49.0-56.0)$ \\
\hline Nevada & 70.0 & $(61.0-79.0)$ & 71.8 & $(67.4-76.2)$ & 52.9 & $(42.2-57.0)$ & 51.2 & $(45.1-57.4)$ \\
\hline New Hampshire & 71.1 & $(63.3-78.9)$ & 65.9 & (62.2-69.5) & 62.1 & $(55.6-66.8)$ & 58.8 & $(53.5-64.2)$ \\
\hline New Jersey & 79.8 & $(75.3-84.3)$ & 71.9 & (69.4-74.3) & 66.4 & $(55.7-64.1)$ & 59.2 & (54.9-63.5) \\
\hline New Mexico & 70.4 & $(64.9-75.8)$ & 69.6 & $(66.9-72.3)$ & 61.7 & $(50.4-60.2)$ & 54.4 & $(50.2-58.5)$ \\
\hline New York & 75.2 & $(69.7-80.7)$ & 73.9 & $(71.0-76.9)$ & 68.6 & $(56.9-69.9)$ & 68.0 & $(63.0-72.9)$ \\
\hline North Carolina & 76.1 & $(71.4-80.8)$ & 69.6 & $(67.1-72.2)$ & 61.6 & $(57.5-65.4)$ & 58.5 & $(54.6-62.5)$ \\
\hline North Dakota & 64.3 & $(57.5-71.2)$ & 61.9 & $(58.3-65.4)$ & 54.6 & $(42.0-54.9)$ & 51.3 & $(46.3-56.3)$ \\
\hline Ohio & 73.6 & $(68.8-78.5)$ & 65.9 & (63.4-68.4) & 57.6 & $(48.3-56.0)$ & 53.1 & $(49.0-57.3)$ \\
\hline Oklahoma & 72.7 & $(67.0-78.3)$ & 68.2 & $(65.6-70.8)$ & 59.1 & $(50.3-59.0)$ & 55.9 & $(52.1-59.7)$ \\
\hline Oregon & 77.7 & $(71.5-84.0)$ & 71.7 & $(68.3-75.2)$ & 60.1 & $(49.5-63.1)$ & 52.5 & $(47.6-57.5)$ \\
\hline Pennsylvania & 75.7 & (71.7-79.8) & 69.0 & $(66.8-71.3)$ & 60.7 & $(54.5-61.8)$ & 58.7 & (55.1-62.3) \\
\hline Rhode Island & 70.4 & $(62.2-78.7)$ & 71.2 & $(67.8-74.6)$ & 63.4 & $(49.8-62.3)$ & 63.4 & $(58.2-68.6)$ \\
\hline South Carolina & 73.8 & $(69.1-78.5)$ & 68.9 & $(66.3-71.5)$ & 63.4 & $(54.3-62.8)$ & 59.6 & $(55.6-63.6)$ \\
\hline South Dakota & 71.9 & $(66.1-77.7)$ & 65.8 & $(62.4-69.3)$ & 52.9 & $(40.5-53.4)$ & 58.2 & $(51.6-64.8)$ \\
\hline Tennessee & 75.7 & $(67.5-84.0)$ & 69.2 & $(65.4-73.1)$ & 62.6 & $(54.6-64.1)$ & 58.4 & $(53.3-63.4)$ \\
\hline Texas & 73.6 & $(68.5-78.7)$ & 72.1 & $(69.5-74.7)$ & 65.0 & $(49.0-60.7)$ & 56.9 & (52.1-61.8) \\
\hline Utah & 75.9 & $(71.1-80.8)$ & 73.6 & $(70.9-76.2)$ & 63.7 & $(51.7-64.0)$ & 59.9 & (54.2-65.5) \\
\hline Vermont & 76.0 & $(69.5-82.4)$ & 66.4 & $(62.8-70.0)$ & 59.6 & $(51.5-63.7)$ & 61.5 & $(56.2-66.7)$ \\
\hline Virginia & 75.4 & $(69.5-81.2)$ & 66.3 & (63.0-69.6) & 60.5 & $(51.3-61.9)$ & 59.8 & (54.9-64.6) \\
\hline Washington & 73.4 & $(68.2-78.5)$ & 69.9 & $(67.3-72.6)$ & 60.3 & $(49.9-58.4)$ & 55.6 & (51.7-59.5) \\
\hline West Virginia & 68.5 & $(62.7-74.4)$ & 57.1 & $(54.1-60.0)$ & 55.0 & $(46.3-55.3)$ & 52.6 & $(48.0-57.2)$ \\
\hline Wisconsin & 81.0 & $(75.1-86.9)$ & 72.9 & (69.3-76.5) & 62.4 & $(52.4-65.8)$ & 56.4 & $(49.0-63.7)$ \\
\hline Wyoming & 69.9 & $(62.9-76.9)$ & 64.7 & (61.0-68.5) & 57.1 & (52.9-66.4) & 51.3 & $(46.3-56.4)$ \\
\hline Median & 73.2 & & 68.7 & & 60.9 & & 56.4 & \\
\hline Guam & 81.4 & (72.4-90.5) & 77.6 & $(73.0-82.2)$ & 67.2 & $(60.5-73.8)$ & 64.8 & $(46.9-82.8)$ \\
\hline Puerto Rico & 76.3 & $(70.0-82.7)$ & 73.6 & $(70.0-77.2)$ & 65.2 & $(61.1-69.3)$ & 61.3 & $(54.6-68.0)$ \\
\hline
\end{tabular}

Abbreviation: $\mathrm{Cl}=$ confidence interval.

* Persons aged $\geq 18$ years who reported having stopped smoking for $\geq 1$ day during the past 12 months because they were trying to quit smoking and were current smokers during time of interview or former smokers who quit during the past year. Data were weighted to be representative of the state and territory population. 


\section{Summary}

What is already known on this topic?

Quitting smoking is beneficial to health at any age, and cigarette smokers who quit before age 35 years have mortality rates similar to those of persons who never smoked.

What is added by this report?

During 2001-2010, the proportion of adult cigarette smokers who had made a quit attempt in the past year increased significantly in 29 states and the U.S. Virgin Islands. During 2011-2013, the proportion who had made a quit attempt increased in Hawaii and Puerto Rico and decreased in New Mexico. In 2013, the proportion who had made a quit attempt ranged from 56.2\% (Kentucky) to 76.4\% (Puerto Rico and Guam) with a median of $65.9 \%$, and was generally lower in older age groups.

What are the implications for public health practice?

Continued implementation of effective evidence-based public health interventions can reduce the health and costs impacts of smoking-related disease and death and accelerate progress toward meeting the Healthy People 2020 target to increase to $\geq 80 \%$ the proportion of U.S. adult cigarette smokers who made a quit attempt in the past year. These interventions include increasing the price of tobacco products, implementing comprehensive smoke-free laws, conducting educational mass media campaigns, and providing insurance coverage for all effective cessation treatments as well as access to quitlines.

those with higher than a high school diploma were more likely to report a quit attempt in the past year than were older persons, whites, and those with less education $(1,8)$. With the requirement by the Patient Protection and Affordable Care Act** that non-grandfathered private insurance plans cover FDA-approved cessation medications, ${ }^{\dagger \dagger}$ access to effective cessation treatments is anticipated to increase.

The findings in this report are subject to at least four limitations. First, only current smokers with an unsuccessful quit attempt in the preceding 12 months were included in the 2001-2010 analysis; therefore, the 2001-2010 data do not provide a complete representation of total past-year quit attempts. Second, during 2001-2010, U.S. adults with

\footnotetext{
** Information on the Affordable Care Act available at http://www.hhs.gov/ healthcare/about-the-law/index.html.

$t^{\dagger}$ Available at http://www.uspreventiveservicestaskforce.org/Page/Name/uspstfa-and-b-recommendations/ - http://www.uspreventiveservicestaskforce.org/ Page/Name/grade-definitions. See also the following: 1) Department of Health and Human Service (HHS) interim final regulations related to grandfathered health plans (June 17, 2010) at 75 FR 34538 (June 17, 2010) and amended interim final regulations at 75 FR 70114 (November 17, 2010); 2) Affordable Care Act, Section 1251, which limits the application of Public Health Services Act section 2707 to non-grandfathered group health plans and health insurance coverage; and 3) May 2014 sub-regulatory guidance from the U.S. departments of HHS, Labor, and Treasury clarifying this provision with regard to tobacco cessation coverage, which defined a comprehensive benefit based on the 2008 PHS Guideline at http://www.dol.gov/ebsa/faqs/faq-aca19.html.
}

wireless-only service (24.5\%) were not included in the survey, although they are twice as likely to smoke cigarettes as the rest of the population (9). Because wireless-only households tend to be a younger demographic and younger persons are more likely to report a quit attempt (1), these data might underestimate actual quit attempts in some states. Third, modeling was limited to linear trends; it is possible that trends for some states are nonlinear. Finally, the median response rate for 2001-2013 ranged from $41.2 \%$ to $54.6 \%$. While lower response rates can increase the potential for bias, national estimates from state-aggregated BRFSS data have been shown to be roughly comparable with smoking estimates from other surveys with higher response rates $(9,10)$.

Examination of state variations can be used to identify effective public health programs and guide programs, promotions, and policies $(2,3)$. To increase the number of cessation attempts, state tobacco control programs can focus their cessation activities on promoting health systems changes that make screening and treatment for tobacco use the standard of care in clinical settings; improving insurance coverage of evidence-based cessation treatments and promoting their use; and increasing use of state quitlines with mass media campaigns that contain graphic anti-smoking ads, such as Tips (3). Other effective interventions for increasing quit attempts and cessation include increasing the unit price of tobacco products and making workplaces and public places smoke-free $(1,3)$. Sustained, comprehensive state tobacco control programs with adequate infrastructure and funded at CDC-recommended levels can accelerate progress toward increasing tobacco cessation and reducing tobacco-related diseases and deaths in the United States (3). ${ }^{1}$ Office on Smoking and Health, National Center for Chronic Disease Prevention
and Health Promotion, CDC, ${ }^{2}$ Contractor, DB Consulting Group, Inc.

Corresponding author: S. René Lavinghouze, rlavinghouze@cdc.gov, 770-488-5905.

\section{References}

1. US Department of Health and Human Services. The health consequences of smoking - 50 years of progress: a report of the Surgeon General. Atlanta, GA: US Department of Health and Human Services, CDC; 2014.

2. CDC. Surveillance for certain health behaviors among states and selected local areas_-United States, 2010. MMWR Surveill Sum 2013;63(SS-01).

3. CDC. Smoking and tobacco use: best practices for comprehensive tobacco control programs - 2014. Atlanta, GA: US Department of Health and Human Services, CDC; 2014. Available at http://www.cdc.gov/tobacco/ stateandcommunity/best_practices.

4. CDC. Methodologic changes in the Behavioral Risk Factor Surveillance System in 2011 and potential effects on prevalence estimates. MMWR Morb Mortal Wkly Rep 2012;61:410-3.

5. Farrelly MC, Pechacek TF, Chaloupka FJ. The impact of tobacco control program expenditures on aggregate cigarette sales: 1981-2000. J Health Econ 2003;22:843-59. 
6. CDC. Increases in quitline calls and smoking cessation website visitors during a national tobacco education campaign-March 19-June 10, 2012. MMWR Morb Mortal Wkly Rep 2012;61:667-70.

7. Schauer GL, Malarcher AM, Zhang L, Engstrom MC, Zhu SH. Prevalence and correlates of quitline awareness and utilization in the United States: an update from the 2009-2010 National Adult Tobacco Survey. Nicotine Tob Res 2014;16:544-53.

8. CDC. Quitting smoking among adults-United States, 2001-2010. MMWR Morb Mortal Wkly Rep 2011;60:1513-9.
9. Blumberg SJ, Luke JV. Wireless substitution: early release of estimates from the National Health Interview Survey, July-December 2009. National Center for Health Statistics; 2010. Available at http://www. cdc.gov/nchs/data/nhis/earlyrelease/wireless201005.pdf.

10. Pierannunzi C, Hu SS, Balluz L. A systematic review of publications assessing reliability and validity of the Behavioral Risk Factor Surveillance System (BRFSS), 2004-2011. BMC medical research methodology 13.1 (2013):49. Available at http://www.biomedcentral. com/1471-2288/13/49. 


\title{
Cigarette, Cigar, and Marijuana Use Among High School Students - United States, 1997-2013
}

\begin{abstract}
Italia V. Rolle, $\mathrm{PhD}^{1}$; Sara M. Kennedy, MPH${ }^{1}$; Israel Agaku, $\mathrm{DMD}^{1}$; Sherry Everett Jones, PhD, JD ${ }^{2}$; Rebecca Bunnell, ScD ${ }^{1}$; Ralph Caraballo, PhD ${ }^{1}$;
\end{abstract} Xin Xu, PhD ${ }^{1}$; Gillian Schauer, MPH${ }^{1}$; Tim McAfee, MD ${ }^{1}$

Since 2010, the proportion of U.S. 12th grade students who used marijuana during the preceding 30 days (21.4\%) has surpassed the proportion who used cigarettes (19.2\%).* Negative outcomes associated with cigarette and marijuana use include addiction to one or both substances and diminished cognitive function, which can lead to lower academic achievement $(1,2)$. Moreover, concurrent use of tobacco and marijuana could thwart prevention and cessation efforts for both products (1). CDC analyzed data from the 1997-2013 national Youth Risk Behavior Surveys (YRBS) among U.S. non-Hispanic white (white), non-Hispanic black (black), and Hispanic students in grades 9-12 to examine trends in the prevalence of current 1) exclusive cigarette or cigar use, 2) exclusive marijuana use, and 3) any use of the three products. CDC further examined the prevalence of current marijuana use among current users of cigarettes or cigars. During 1997-2013, exclusive cigarette or cigar use declined overall by $64 \%$, from $20.5 \%$ to $7.4 \%(p<0.01)$. However, exclusive marijuana use more than doubled overall from $4.2 \%$ to $10.2 \%$ ( $\mathrm{p}<0.01)$. Any cigarette, cigar, or marijuana use decreased overall from $46.1 \%$ to $29.9 \%(\mathrm{p}<0.01)$, whereas marijuana use among cigarette or cigar users increased from $51.2 \%$ to $62.4 \%$. Considerable increases were identified among black and Hispanic students toward the end of the study period for exclusive marijuana use and marijuana use among cigarette or cigar users. Increased exclusive marijuana use and use of marijuana among cigarette or cigar users could undermine success in reducing tobacco use among youths. Closer collaboration between public health professionals to address prevention of tobacco and marijuana use might be beneficial in the development of evidence-based policies and programs to prevent tobacco and marijuana use.

The national YRBS is a biennial cross-sectional survey of U.S. public and private school students in grades 9-12, administered in a classroom setting using a paper and pencil questionnaire. $\mathrm{CDC}$ examined trends in the prevalence of current 1) exclusive use of cigarettes or cigars; 2) exclusive use of marijuana; and 3) any use of cigarettes, cigars, or marijuana among white, black, and Hispanic students. CDC also examined the prevalence of current marijuana use among current users of cigarettes or cigars. Records with missing data for cigarette use, cigar use, marijuana use, race/ethnicity, or sex,

\footnotetext{
*Additional information available at http://www.monitoringthefuture.org/ data/14data.html.
}

were excluded from the analysis. The analytic data set was further restricted to students self-identifying as black, white, or Hispanic, resulting in final analytic sample sizes ranging from 11,050 (2013) to 13,242 (2009). ${ }^{\dagger}$

Current use was defined as smoking cigarettes or cigars on $\geq 1$ days, or using marijuana one or more times, during the 30 days preceding the survey. ${ }^{\S}$ Exclusive cigarette or cigar use was defined as current use of cigarettes or cigars, but not marijuana. Exclusive marijuana use was defined as current use of marijuana, but not cigarettes or cigars. Any cigarette, cigar, or marijuana use was defined as current use of any of the three products. Among current cigarette or cigar users, the proportion of current marijuana users was assessed. Trends in exclusive cigarette or cigar use, exclusive marijuana use, any use of these products, and marijuana use among current cigarette or cigar users, were assessed among all students in the analytic sample overall, by sex, and by race/ethnicity. Data were assessed for the presence of linear trends using logistic regression analyses that adjusted for race/ethnicity, sex, and grade; $\mathrm{p}<0.05$ was used to determine statistical significance. A significant linear trend indicated an overall increase or decrease during the study period. Data also were assessed for the presence of quadratic trends. A significant quadratic trend indicated a leveling off or change in direction of a trend line. Logistic regression models testing trends for students overall controlled for race/ethnicity, sex, and grade. Models among racial/ethnic subgroups controlled for sex and grade, models for sex subgroups controlled for race/ethnicity and grade. When a significant quadratic trend was found, Joinpoint software was used to identify the year in

\footnotetext{
$\dagger$ In each survey year, a similar independent three-stage cluster sample design was used to obtain a nationally representative sample of public and private school students in grades 9-12 in the 50 states and the District of Columbia. During 1997-2013, total sample sizes and overall response rates (the product of the school and student response rate) for each survey year were as follows: 1997 $(16,262$; response rate $=69 \%) ; 1999(15,349 ; 66 \%) ; 2001(13,601 ; 63 \%)$; 2003 (15,214; 67\%); 2005 (13,917; 67\%); 2007 (14,041; 68\%); 2009 (16,410; $71 \%) ; 2011(15,425 ; 71 \%) ; 2013(13,583 ; 68 \%)$. This analysis was restricted to non-Hispanic white, non-Hispanic black, and Hispanic students because of previously reported differences in the use of cigarettes, cigars, and marijuana by these groups.

$\S$ Current use of cigarettes, cigars, or marijuana was assessed with the following respective questions: "During the past 30 days, on how many days did you smoke cigarettes?" "During the past 30 days, on how many days did you smoke any cigars, cigarillos, or little cigars?" and "During the past 30 days, how many times did you use marijuana?" Respondents with missing data for cigarette, cigar, or marijuana use questions were excluded from the analysis (9\%).
} 
which the leveling off or change in direction occurred. Then logistic regression analyses were used to assess the presence of a significant linear trend in each segment.

During 1997-2013, linear decreases occurred in exclusive cigarette or cigar use among students overall, and among all sex and racial/ethnic subgroups $(\mathrm{p}<0.01)$, with an overall percentage decrease of $64 \%$ (Table) (Figure 1). Linear increases occurred in exclusive marijuana use among students overall, and among all sex and racial/ethnic subgroups, with an overall increase from $4.2 \%$ to $10.2 \%$ ( $\mathrm{p}<0.01$ ) (Table). In addition, quadratic trends in exclusive marijuana use were identified among black and Hispanic students $(\mathrm{p}<0.01)$. Among black and Hispanic students, exclusive marijuana use did not change

\footnotetext{
National Cancer Institute. Joinpoint regression program, 2013. Additional
} information available at http://surveillance.cancer.gov/joinpoint. from 1997 to 2009 (9.2\% to $10.9 \%$ and $5.9 \%$ to $8.5 \%$, respectively), but increased from 2009 to 2013 (10.9\% to $16.6 \%$ and $8.5 \%$ to $14.2 \%$, respectively).

Linear decreases and quadratic trends occurred in any cigarette, cigar, or marijuana use among students overall, and among all sex and racial /ethnic subgroups $(\mathrm{p}<0.01)$ (Table). Among students overall, any cigarette, cigar, or marijuana use decreased from 1997 to 2007 (46.1\% to 29.8\%), but did not change from 2007 to 2013 (29.8\% to $29.9 \%)$. Among white students, any cigarette, cigar, or marijuana use decreased from 1997 to 2005 (48.0\% to $34.1 \%$ ), and then decreased more gradually from 2005 to 2013 (34.1\% to 29.8\%). Among black students, any cigarette, cigar, or marijuana use decreased from 1997 to 2007 (38.3\% to $25.0 \%$ ), and then increased from 2007 to 2013 (25.0\% to 30.0\%); whereas, among Hispanic

TABLE. Prevalence of exclusive cigarette or cigar use ${ }^{*}$; exclusive marijuana use ${ }^{\dagger}$; any cigarette, cigar, or marijuana use ${ }^{\S}$; and marijuana use among high school students" who used cigarettes or cigars during the 30 days preceding the surveys, by sex and selected race/ethnicity National Youth Risk Behavior Surveys, United States, 1997-2013

\begin{tabular}{|c|c|c|c|c|}
\hline & 1997 & 1999 & 2001 & 2003 \\
\hline Sex/Race/Ethnicity & $\%(95 \% \mathrm{Cl})$ & $\%(95 \% \mathrm{Cl})$ & $\%(95 \% \mathrm{Cl})$ & $\%(95 \% \mathrm{CI})$ \\
\hline \multicolumn{5}{|c|}{ Exclusive cigarette or cigar use } \\
\hline Total & $20.5(17.9-23.3)$ & $18.3(15.6-21.3)$ & $13.9(12.5-15.4)$ & $11.8(10.5-13.4)$ \\
\hline \multicolumn{5}{|l|}{ Sex } \\
\hline Male & $21.4(17.8-25.6)$ & $18.3(15.2-21.9)$ & $13.8(12.2-15.6)$ & $11.9(10.1-13.9)$ \\
\hline Female & $19.3(16.9-22.0)$ & $18.2(15.4-21.5)$ & $13.9(12.2-15.8)$ & $11.8(10.2-13.6)$ \\
\hline \multicolumn{5}{|l|}{ Race/Ethnicity } \\
\hline White, non-Hispanic & $23.0(20.1-26.2)$ & $20.8(17.5-24.5)$ & 15.5 (13.9-17.2) & $13.8(12.2-15.5)$ \\
\hline Black, non-Hispanic & $10.6(8.3-13.3)$ & $9.9(8.1-12.0)$ & $6.1(4.7-8.1)$ & $6.8(5.1-9.0)$ \\
\hline Hispanic & $15.5(12.9-18.5)$ & $14.4(12.3-16.7)$ & $12.5(10.0-15.5)$ & $8.4(6.3-10.9)$ \\
\hline \multicolumn{5}{|c|}{ Exclusive marijuana use } \\
\hline Total & $4.2(3.3-5.2)$ & $5.7(4.5-7.2)$ & $5.7(5.1-6.4)$ & $7.3(6.3-8.4)$ \\
\hline \multicolumn{5}{|l|}{ Sex } \\
\hline Male & $4.7(3.8-5.9)$ & $6.9(5.0-9.5)$ & $6.5(5.7-7.4)$ & $8.2(7.0-9.7)$ \\
\hline Female & $3.6(2.7-4.7)$ & $4.5(3.7-5.4)$ & $5.0(4.3-5.7)$ & $6.3(5.3-7.5)$ \\
\hline \multicolumn{5}{|l|}{ Race/Ethnicity } \\
\hline White, non-Hispanic & $3.0(2.2-4.3)$ & $4.3(3.0-6.0)$ & $4.8(4.2-5.5)$ & $5.9(4.9-7.1)$ \\
\hline Black, non-Hispanic & $9.2(7.1-11.7)$ & $11.0(7.9-15.2)$ & $8.7(6.6-11.5)$ & $10.6(8.9-12.7)$ \\
\hline Hispanic & $5.9(4.4-7.9)$ & $7.5(5.4-10.3)$ & $7.8(6.4-9.3)$ & $9.8(8.1-11.9)$ \\
\hline \multicolumn{5}{|c|}{ Any cigarette or cigar or marijuana use } \\
\hline Total & $46.1(44.2-48.1)$ & $44.6(42.3-47.0)$ & $37.6(35.9-39.2)$ & 33.6 (31.4-35.9) \\
\hline \multicolumn{5}{|l|}{ Sex } \\
\hline Male & $50.5(48.3-52.7)$ & $48.5(45.7-51.2)$ & $41.4(39.5-43.3)$ & $36.0(33.6-38.4)$ \\
\hline Female & $40.9(37.9-44.0)$ & 40.7 (37.9-43.6) & $34.0(32.0-36.0)$ & $31.1(28.5-33.8)$ \\
\hline \multicolumn{5}{|l|}{ Race/Ethnicity } \\
\hline White, non-Hispanic & $48.0(45.7-50.2)$ & $47.0(44.3-49.7)$ & $39.6(37.9-41.3)$ & $35.1(32.6-37.7)$ \\
\hline Black, non-Hispanic & $38.3(35.2-41.5)$ & $35.7(29.3-42.7)$ & $27.3(23.1-31.9)$ & $29.5(26.1-33.1)$ \\
\hline Hispanic & $43.4(39.6-47.3)$ & $42.2(37.1-47.4)$ & $36.3(33.3-39.4)$ & $31.0(27.7-34.6)$ \\
\hline \multicolumn{5}{|c|}{ Marijuana use among cigarette or cigar users } \\
\hline Total & $51.2(46.0-56.3)$ & $53.0(47.8-58.2)$ & $56.5(52.8-60.1)$ & $55.0(51.5-58.6)$ \\
\hline \multicolumn{5}{|l|}{ Sex } \\
\hline Male & $53.2(46.1-60.1)$ & $55.9(49.8-61.8)$ & $60.5(56.4-64.4)$ & $57.3(53.0-61.4)$ \\
\hline Female & $48.2(43.6-52.8)$ & $49.7(44.2-55.2)$ & $52.0(47.5-56.4)$ & $52.5(48.7-56.3)$ \\
\hline \multicolumn{5}{|l|}{ Race/Ethnicity } \\
\hline White, non-Hispanic & $48.8(43.1-54.4)$ & $51.4(45.5-57.2)$ & $55.5(51.3-59.7)$ & $52.8(48.5-57.0)$ \\
\hline Black, non-Hispanic & $63.7(57.3-69.7)$ & $60.0(51.9-67.6)$ & $66.9(57.5-75.0)$ & $64.0(56.3-71.1)$ \\
\hline Hispanic & $58.6(51.8-65.2)$ & $58.6(52.9-63.9)$ & $56.2(51.1-61.2)$ & $60.6(54.0-66.8)$ \\
\hline
\end{tabular}

See table footnotes on the next page. 
TABLE. (Continued) Prevalence of exclusive cigarette or cigar use*; exclusive marijuana use ${ }^{\dagger}$; any cigarette, cigar, or marijuana use ${ }^{\S}$; and marijuana use among high school students" who used cigarettes or cigars during the 30 days preceding the surveys, by sex and selected race/ ethnicity — National Youth Risk Behavior Surveys, United States, 1997-2013

\begin{tabular}{|c|c|c|c|c|c|}
\hline & 2005 & 2007 & 2009 & 2011 & 2013 \\
\hline Sex/Race/Ethnicity & $\%(95 \% \mathrm{Cl})$ & $\%(95 \% \mathrm{Cl})$ & $\%(95 \% \mathrm{Cl})$ & $\%(95 \% \mathrm{Cl})$ & $\%(95 \% \mathrm{Cl})$ \\
\hline \multicolumn{6}{|c|}{ Exclusive cigarette or cigar use } \\
\hline Total & $12.3(10.9-13.9)$ & $10.6(9.2-12.1)$ & $10.2(8.8-11.8)$ & $8.4(7.5-9.5)$ & $7.4(6.0-9.1)^{* *}$ \\
\hline \multicolumn{6}{|l|}{ Sex } \\
\hline Male & $13.2(11.6-15.0)$ & $11.6(9.7-13.9)$ & $10.7(9.0-12.7)$ & $9.0(7.9-10.3)$ & $8.4(6.7-10.4)^{* *}$ \\
\hline Female & $11.4(9.9-13.1)$ & $9.5(8.3-10.8)$ & $9.7(8.5-11.0)$ & $7.9(6.7-9.2)$ & $6.5(5.1-8.2)^{* *}$ \\
\hline \multicolumn{6}{|l|}{ Race/Ethnicity } \\
\hline White, non-Hispanic & $14.3(12.5-16.4)$ & $12.5(10.9-14.2)$ & $12.4(10.5-14.6)$ & $10.0(8.8-11.3)$ & $9.8(8.0-11.9)^{* *}$ \\
\hline Black, non-Hispanic & $5.9(4.8-7.3)$ & $4.6(3.5-6.1)$ & $5.1(3.9-6.7)$ & $3.5(2.5-4.9)$ & $2.4(1.6-3.5)^{* *}$ \\
\hline Hispanic & $9.3(7.7-11.2)$ & $8.6(6.8-11.0)$ & $6.9(5.7-8.3)$ & $7.1(5.8-8.6)$ & $4.2(3.1-5.7)^{* *}$ \\
\hline \multicolumn{6}{|c|}{ Exclusive marijuana use } \\
\hline Total & $5.6(4.9-6.5)$ & $5.9(4.9-7.0)$ & $7.0(6.1-8.0)$ & $8.8(7.7-10.0)$ & $10.2(8.6-12.0)^{* *}$ \\
\hline \multicolumn{6}{|l|}{ Sex } \\
\hline Male & $6.2(5.2-7.4)$ & $6.4(5.5-7.5)$ & $7.7(6.9-8.7)$ & $9.1(7.9-10.4)$ & $10.3(8.8-11.9)^{* *}$ \\
\hline Female & $5.1(4.2-6.1)$ & $5.3(4.1-6.8)$ & $6.2(5.1-7.5)$ & $8.4(7.1-9.9)$ & $10.1(8.3-12.3)^{* *}$ \\
\hline \multicolumn{6}{|l|}{ Race/Ethnicity } \\
\hline White, non-Hispanic & $4.5(3.6-5.6)$ & $4.8(3.8-6.0)$ & $5.6(4.6-6.8)$ & $7.1(5.8-8.7)$ & $7.1(5.6-9.0)^{* *}$ \\
\hline Black, non-Hispanic & $9.6(8.1-11.3)$ & $9.5(7.5-12.1)$ & $10.9(8.8-13.4)$ & $13.2(11.6-14.9)$ & $16.6(14.9-18.5)^{* *+\dagger}$ \\
\hline Hispanic & $7.2(5.9-8.6)$ & $6.8(5.7-8.3)$ & $8.5(7.3-9.9)$ & $10.8(9.2-12.6)$ & $14.2(12.4-16.2)^{* *+\dagger}$ \\
\hline \multicolumn{6}{|c|}{ Any cigarette or cigar or marijuana use } \\
\hline Total & $32.4(29.9-35.1)$ & $29.8(27.4-32.3)$ & $30.5(28.9-32.2)$ & $30.4(28.7-32.1)$ & $29.9(27.6-32.2)^{* * \dagger+}$ \\
\hline \multicolumn{6}{|l|}{ Sex } \\
\hline Male & $34.8(32.2-37.6)$ & 33.7 (30.5-37.0) & $33.4(31.3-35.5)$ & $33.8(31.8-35.8)$ & $32.7(30.5-35.1)^{* *+\dagger}$ \\
\hline Female & $30.0(27.2-33.0)$ & $25.9(23.6-28.4)$ & $27.4(25.5-29.4)$ & $26.8(24.7-29.0)$ & $27.1(24.4-29.9)^{* *+\dagger}$ \\
\hline \multicolumn{6}{|l|}{ Race/Ethnicity } \\
\hline White, non-Hispanic & $34.1(30.8-37.5)$ & $31.9(29.1-34.8)$ & $32.3(30.1-34.5)$ & 31.1 (28.9-33.3) & $29.8(26.7-33.0)^{* * \dagger \dagger}$ \\
\hline Black, non-Hispanic & $25.5(23.1-28.1)$ & $25.0(22.1-28.2)$ & $26.2(23.4-29.1)$ & $28.0(24.9-31.3)$ & $30.0(27.1-33.0)^{* *+\dagger}$ \\
\hline Hispanic & $31.4(28.1-34.9)$ & $26.0(22.3-30.1)$ & $27.9(25.4-30.5)$ & $29.7(27.0-32.7)$ & $30.1(26.7-33.7)^{* *+\dagger}$ \\
\hline \multicolumn{6}{|c|}{ Marijuana use among cigarette or cigar users } \\
\hline Total & $54.1(51.2-56.9)$ & $55.8(51.9-59.6)$ & $56.6(52.4-60.6)$ & $60.9(57.2-64.5)$ & $62.4(57.5-67.1)^{* *}$ \\
\hline \multicolumn{6}{|l|}{ Sex } \\
\hline Male & $54.0(50.2-57.7)$ & $57.2(52.8-61.5)$ & $58.2(53.0-63.3)$ & $63.5(59.0-67.8)$ & $62.8(56.8-68.5)^{* *}$ \\
\hline Female & $54.2(50.3-58.0)$ & $53.9(49.6-58.1)$ & $54.3(50.6-58.0)$ & $57.3(52.4-62.0)$ & $61.9(56.0-67.6)^{* *}$ \\
\hline \multicolumn{6}{|l|}{ Race/Ethnicity } \\
\hline White, non-Hispanic & $51.6(48.6-54.6)$ & $54.0(49.5-58.5)$ & $53.6(48.6-58.4)$ & $58.4(53.8-62.8)$ & $56.7(51.3-62.0)^{* *}$ \\
\hline Black, non-Hispanic & $62.9(56.0-69.3)$ & $70.5(64.5-75.8)$ & $66.4(59.3-72.9)$ & $76.2(69.2-82.0)$ & $82.0(76.0-86.7)^{* *+\dagger}$ \\
\hline Hispanic & $61.6(56.6-66.4)$ & $54.9(49.3-60.3)$ & $64.4(59.1-69.5)$ & $62.6(57.7-67.3)$ & $73.6(68.1-78.4)^{* *+\dagger}$ \\
\hline
\end{tabular}

Abbreviation: $\mathrm{Cl}=$ confidence interval.

* Used cigarettes or cigars on one or more days, but did not use marijuana during the 30 days preceding the surveys.

† Used marijuana one or more times, but did not use cigarettes or cigars during the 30 days preceding the surveys.

$\S$ Used cigarettes or cigars on one or more days, or used marijuana one or more times during the 30 days preceding the surveys.

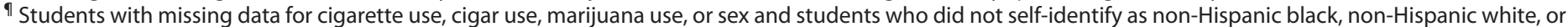
Hispanic were excluded from the analysis.

** Significant linear trend during 1997-2013 $(p<0.01)$.

†† Significant quadratic trend during 1997-2013 ( $p<0.01)$.

students, any cigarette, cigar, or marijuana use decreased from 1997 to 2007 (43.4\% to $26.0 \%)$, and then did not change from 2007 to 2013 (26.0\% to $30.1 \%)$.

During 1997-2013, linear increases occurred in the proportion of cigarette or cigar users who used marijuana among students overall $(51.2 \%$ to $62.4 \%)$, and among all sex and racial/ethnic subgroups ( $\mathrm{p}$ for trend $<0.01$ ) (Figure 2). In addition, a quadratic trend was identified among black and Hispanic students $(\mathrm{p}<0.01)$. Among cigarette or cigar users, use of marijuana did not change among black students from
1997 to 2009 (63.7\% to 66.4\%) or Hispanic students from 1997 to 2007 (58.6\% to 54.9\%), but increased among black students from 2009 to $2013(66.4 \%$ to $82.0 \%)$ and among Hispanic students from 2007 to 2013 (54.9\% to 73.6\%).

\section{Discussion}

From 1997 to 2013, a 64\% percent decrease occurred in the percentage of U.S. white, black, and Hispanic high school students overall who used cigarettes or cigars exclusively. Additionally, among white students, any cigarette, cigar, or 
FIGURE 1. Prevalence of exclusive cigarette or cigar use, ${ }^{* \dagger}$ exclusive marijuana use, $+\S$ and any cigarette, cigar, or marijuana use ${ }^{\dagger \uparrow * *}$ among high school students ${ }^{\dagger \dagger}$ during the 30 days preceding the surveys - National Youth Risk Behavior Surveys, United States, 1997-2013

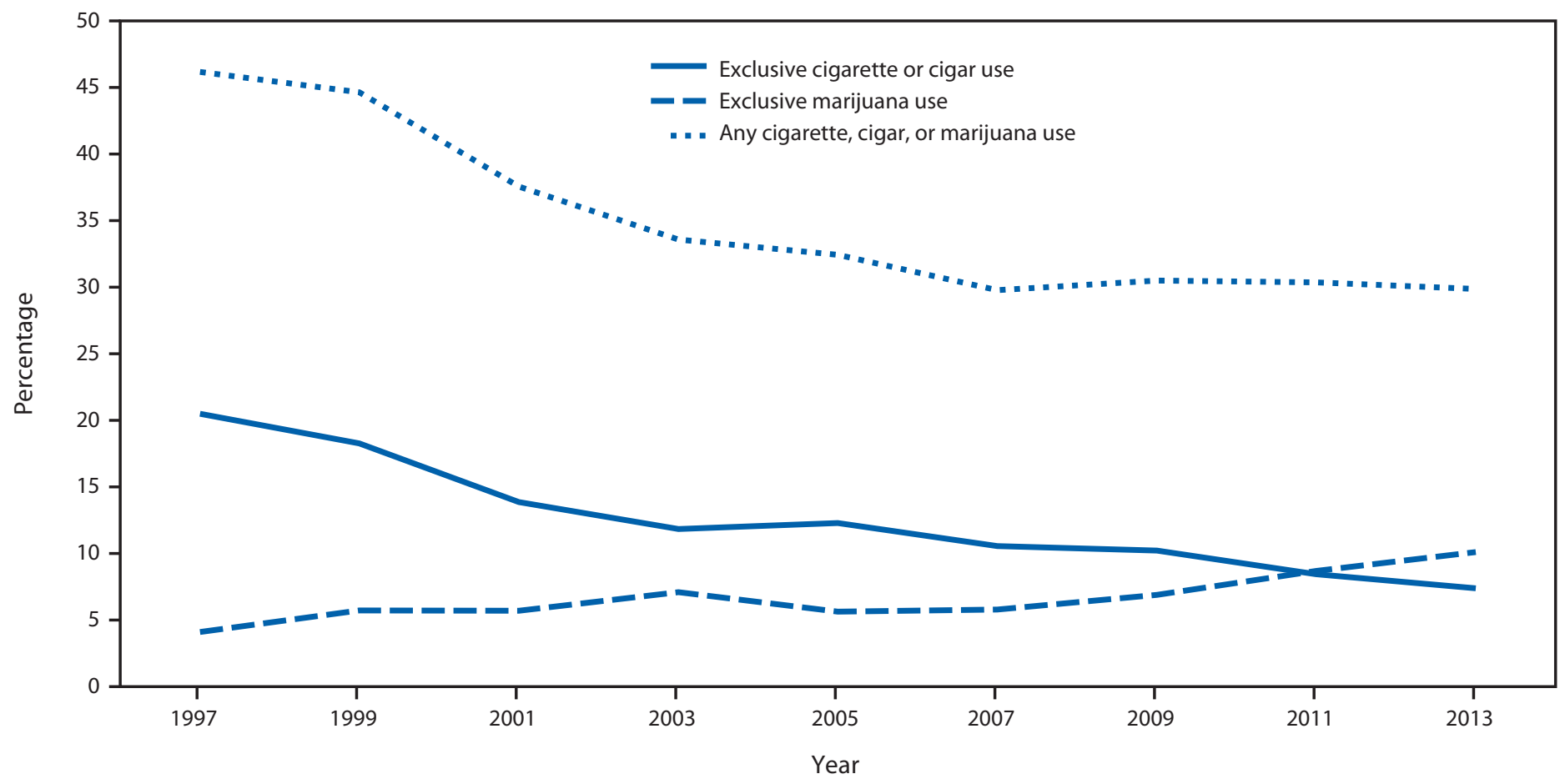

* Used cigarettes or cigars on one or more days, but did not use marijuana during the 30 days preceding the survey.

† Significant linear trend during 1997-2013 ( $p<0.01)$.

§ Used marijuana one or more times, but did not use cigarettes or cigars during the 30 days preceding the survey.

I Significant quadratic trend during 1997-2013 ( $p<0.01)$.

** Used cigarettes or cigars on one or more days, or used marijuana one or more times during the 30 days preceding the survey.

${ }^{+\dagger}$ Students with missing data for cigarette use, cigar use, marijuana use, or sex and students who did not self-identify as non-Hispanic black, non-Hispanic white, or Hispanic were excluded from the analysis.

marijuana use decreased during the study period. Among black and Hispanic students, any cigarette, cigar, or marijuana use decreased from 1997 to 2007, but increased among black students from 2007 to 2013, and did not change for Hispanics from 2007 to 2013. Moreover, the percentage of white, black, and Hispanic students overall who were exclusive marijuana users more than doubled, and marijuana use among cigarette or cigar users also increased, with substantial increases identified among black and Hispanic students toward the end of the study period. Thus, public health advances in adolescent health resulting from lower cigarette and cigar use might be attenuated by increases in marijuana use, which vary by racial/ ethnic subgroup.

Tobacco prevention and control strategies, including increasing tobacco product prices, adopting comprehensive smokefree laws, and implementing national public education media campaigns, have influenced the reduction in youth cigarette smoking. .* Increases in marijuana use among U.S. youths might be attributable to decreasing perceptions of harm from

\footnotetext{
** Additional information available at http://www.cdc.gov/tobacco/ stateandcommunity/best_practices/.
}

1991 to 2013 (from $78.6 \%$ to $39.5 \%$ ). ${ }^{\dagger \dagger}$ More specifically, decriminalization and legalization of recreational marijuana use in some states with minimal concomitant public health messaging to address potential detrimental health effects of marijuana use might be contributing to this perception (3). Further, legalization of medical marijuana use in 24 states, the District of Columbia, and Guam might increase perceptions of benefits of use, including that it is not harmful (4). $\$ \$$

Public health concerns about the recreational use of marijuana among adolescents is related, in part, to the potential for harm to individual users and the potential for marijuana to be a "gateway" to the use of tobacco and other illicit drugs or substances (1). The amount of contaminants (e.g., tar and polycyclic aromatic hydrocarbons) inhaled from smoked marijuana can be more than double that of smoked tobacco (1). When marijuana is used concurrently with tobacco, the likelihood of individual-level harm, including cognitive, psychological, respiratory, and addiction problems, increases (1).

\footnotetext{
$\dagger$ Additional information available at http://www.monitoringthefuture.org/ pubs/monographs/mtf-overview2013.pdf.

$\$ \mathbb{S}$ Additional information available at http://www.ncsl.org/research/health/ state-medical-marijuana-laws.aspx.
} 
FIGURE 2. Prevalence of current marijuana use* among white, black, and Hispanic high school students ${ }^{\dagger}$ who were current cigarette or cigar users $^{\S}$ — National Youth Risk Behavior Surveys, ${ }^{\circledR}$ United States, 1997-2013

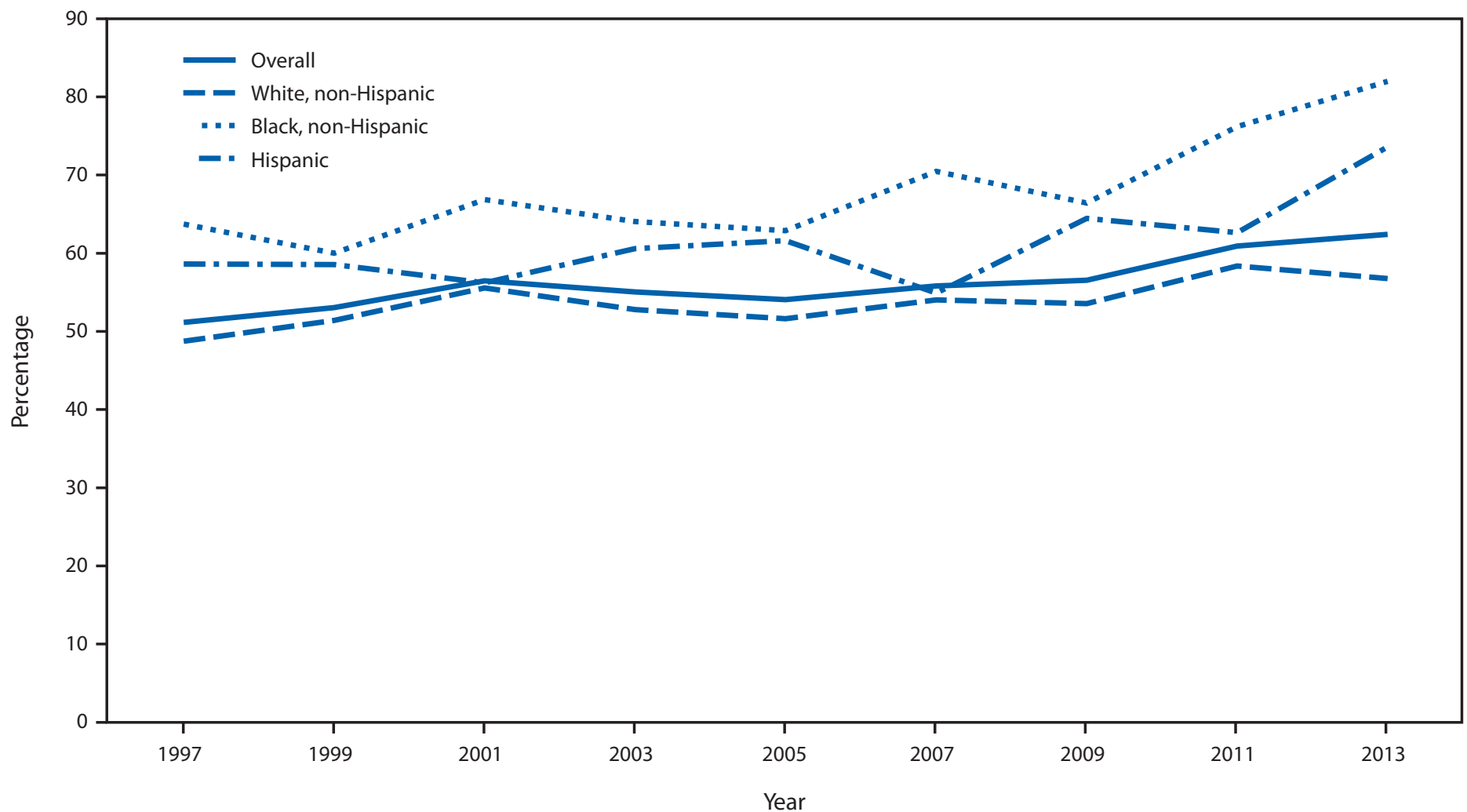

* Used marijuana one or more times during the 30 days preceding the survey.

† Students with missing data for cigarette use, cigar use, marijuana use, or sex and students who did not self-identify as non-Hispanic black, non-Hispanic white, or Hispanic were excluded from the analysis.

$\S$ Used cigarettes or cigars on one or more days during the 30 days preceding the survey.

" Significant linear trends were identified for all groups $(p<0.01)$, and significant quadratic trends were identified among non-Hispanic black and Hispanic students $(p<0.01)$ during 1997-2013.

The findings in this report are subject to at least five limitations. First, marijuana, cigarette, and cigar use were self-reported and not confirmed with biochemical tests, so the extent of underreporting or overreporting is unknown. Second, YRBS did not measure hookah use, which is an increasing mode of combustible tobacco use among youths, independently associated with marijuana use, and as such may offset declines in cigarette or cigar use $(5,6)$. Third, YRBS did not measure use of electronic nicotine delivery systems such as e-cigarettes, hookahs, and vape pens (portable devices that function like e-cigarettes, but permit the user to add dry herbs, oils, or waxes) that are capable of aerosolizing marijuana $(5,7)$. Fourth, YRBS did not measure blunt use, a popular product among youths and young adults, in which some or most of the tobacco in a cigar is taken out and replaced by marijuana (8). Finally, these data apply only to white, black, and Hispanic youths who attended school and, therefore, are not representative of all persons in this age group. However, nationwide, in 2009, approximately $96 \%$ of persons aged 16-17 years were enrolled in a high school program (9).
Reducing current use of cigarettes, cigars, and marijuana among U.S. youths might be achieved through multifaceted, targeted implementation of evidence-based program and policy interventions, in concert with active engagement of multiple stakeholders, including parents, schools, communities, and the media (10). Enhanced and sustained tobacco and marijuana use surveillance can help in monitoring trends and patterns of use, including the measurement of progress toward achieving Healthy People 2020 objectives 99 related to the use of these substances among youth. Policy and programmatic efforts might benefit from approaches that focus on reducing the use of tobacco and marijuana among youth.

$\overline{99}$ Available at http://www.healthypeople.gov/2020/topics-objectives.

${ }^{1}$ Office on Smoking and Health, National Center for Chronic Disease Prevention and Health Promotion, CDC; ${ }^{2}$ Division of Adolescent and School Health, National Center for HIV/AIDS, Viral Hepatitis, STD, and TB Prevention, CDC.

Corresponding author: Italia Rolle, itr2@cdc.gov, 770-488-1134. 


\section{References}

1. Agrawal A, Budney AJ, Lynskey MT. The co-occurring use and misuse of cannabis and tobacco: a review. Addiction 2012;107:1221-33.

2. Stiby AI, Hickman M, Munafo MR, Heron J, Yip VL, Macleod J. Adolescent cannabis and tobacco use and educational outcomes at age 16: birth cohort study. Addiction 2015;110:658-68.

3. Committee on Substance Abuse, Committee on Adolescence. The impact of marijuana policies on youth: clinical, research, and legal update. Pediatrics 2015;135:584-7.

4. Palamar JJ, Ompad DC, Petkova E. Correlates of intentions to use cannabis among US high school seniors in the case of cannabis legalization. Int J Drug Policy 2014;25:424-35.

5. Arrazola RA, Singh T, Corey CG, et al. Tobacco use among middle and high school students-United States, 2011-2014. MMWR Morb Mortal Wkly Rep 2015;64:381-5.

6. Palamar JJ, Zhou S, Sherman S, Weitzman M. Hookah use among US high school seniors. Pediatrics 2014;134:227-34.

7. Malouff JM, Rooke SE, Copeland J. Experiences of marijuana-vaporizer users. Subst Abus 2014;35:127-8.

8. Jones PR, Cohen MZ, McIlvain HE, Siahpush M, Scott A, Okafor K. Smoking in young adult African Americans. J Adv Nurs 2014; 70:1117-27.

9. Chapman C, Laird J, Ifill N, KewalRamani A. Trends in high school dropout and completion rates in the United States: 1972-2009 (NCES 2012-006). Washington, DC: National Center for Education Statistics, US Department of Education; 2011. Available at http://nces.ed.gov/ pubs2012/2012006.pdf.

10. Ehrenreich H, Nahapetyan L, Orpinas P, Song X. Marijuana use from middle to high school: co-occurring problem behaviors, teacherrated academic skills and sixth-grade predictors. J Youth Adolesc 2014;44:1929-40.

\section{Summary}

What is already known on this topic?

Since 2010, the proportion of U.S. 12th grade students who reported using marijuana during the preceding 30 days (21.4\%) has surpassed the proportion reporting use of cigarettes during the preceding 30 days (19.2\%).

What is added by this report?

During 1997-2013, the proportion of white, black, and Hispanic high school students overall who were exclusive cigarette or cigar users decreased $64 \%$, from $20.5 \%$ to $7.4 \%$. The proportion of white, black, and Hispanic students who were exclusive marijuana users more than doubled from $4.2 \%$ to $10.2 \%$, and among cigarette or cigar users, marijuana use increased, with considerable increases identified among black and Hispanic students toward the end of the study period.

What are the implications for public health practice?

Despite significant declines since 1997, approximately $30 \%$ of white, black, and Hispanic U.S. high school students were current users of cigarettes, cigars, or marijuana in 2013. Policy and programmatic efforts might benefit from integrated approaches that focus on reducing the use of tobacco and marijuana among youths. 


\title{
Use of Surveillance Systems in Detection of a Ciguatera Fish Poisoning Outbreak — Orange County, Florida, 2014
}

\author{
Benjamin G. Klekamp, $\mathrm{MSPH}^{1}$; Dean Bodager, $\mathrm{MPA}^{2}$; Sarah D. Matthews, $\mathrm{MPH}^{1}$
}

Ciguatera fish poisoning (CFP) is a foodborne illness acquired by eating predatory reef fish that have accumulated naturally occurring ciguatoxins found in several dinoflagellate (algae) species through their diet. CFP produces neuropsychiatric, neurologic, cardiovascular, and gastrointestinal signs and symptoms, and is one of the most commonly reported fishassociated marine intoxications. Ciguatoxin retains toxicity regardless of freezing or cooking. Prompt treatment can reduce debilitating neurologic symptoms that are associated with CFP. On November 3, 2014, the Florida Department of Health in Orange County (DOH-Orange) received a report through the $\mathrm{DOH}$ online foodborne illness complaint system from a person (patient $\mathrm{A}$ ) describing paresthesias and numbness that suggested CFP, which had occurred on October 31, the day after eating two fish meals. The day the report was received, $\mathrm{DOH}$-Orange interviewed patient $\mathrm{A}$ and determined that her illness met the CFP case definition. In Florida, a single case of CFP is considered an outbreak. Multiple data sources were used to identify five additional CFP cases. DOH-Orange, the $\mathrm{DOH}$ Bureau of Epidemiology, the Florida Department of Business and Professional Regulation (DBPR), the Florida Department of Agriculture and Consumer Services (DACS), and the U.S. Food and Drug Administration (FDA) collaborated to conduct investigations at two restaurants, one grocery store, two fish distributors, and one fish supplier to identify the outbreak food source. The six persons with CFP had eaten black grouper either at a local restaurant or purchased from a grocery store; the fish was traced back to a common international distributor. Rapid identification and reporting of CFP cases to public health officials is imperative to facilitate supportive medical care $(1,2)$ and source-food traceback efforts.

The initial investigation by DOH-Orange identified patient $A$ as an adult female non-Florida resident, who reported consuming mahi-mahi at restaurant $\mathrm{A}$ on October 30 at 3:00 p.m., and a black grouper filet at restaurant $B$ at 7:45 p.m. the same day. No leftover fish was available from either meal. Patient A dined alone at restaurant A, but ate with three other persons at restaurant B. No food was shared at restaurant $\mathrm{B}$, and although one other group member also consumed a separate black grouper filet, only patient A became ill. On October 31 at 3:00 a.m., approximately 7 hours after eating the grouper at restaurant $B$, patient $A$ experienced acute onset of paradoxical temperature perception, paresthesias, extremity numbness, a metallic taste, nausea, vomiting, abdominal pain, diarrhea, arthralgia, and myalgia. A hotel physician evaluated the patient but did not provide a diagnosis. Patient A's signs and symptoms, including paradoxical temperature perception, paresthesias, fever, dizziness, nausea, vomiting, and diarrhea continued, and she reported her illness to the $\mathrm{DOH}$ online foodborne illness complaint system on November 3.

To identify additional associated CFP cases, DOH-Orange queried surveillance systems, including emergency department chief complaint records, poison control center reports, and reportable disease data through the Electronic Surveillance System for the Early Notification of Community-Based Epidemics-Florida (ESSENCE-FL), and reviewed foodborne illness complaints to $\mathrm{DOH}$ through phone, fax, and online report submission. On November 6, DOH-Orange received an automatic e-mail alert from ESSENCE-FL stating that on November 5, within a period of 22 minutes, four persons had visited one Orange County emergency department for "food poisoning." Review of medical records faxed the following day indicated the four persons all lived at the same local address and had symptoms of nausea, diarrhea, and vomiting. A notation that the patient had become ill after eating "bad fish" was found in all four medical records. No laboratory tests were ordered, and no medication was prescribed; the patients were discharged with diagnoses of gastroenteritis. On November 7, while DOH-Orange was interviewing the four ill patients, a fifth ill adult household member who had not sought medical attention was identified. All five household members (patients B, C, D, E, and F) shared a meal of black grouper fish heads on November 3. The fish heads were purchased from grocery store A on the same day they were consumed. The patients reported that symptoms began approximately 3 hours after the meal, and, in addition to the gastrointestinal symptoms reported in the hospital emergency department, they experienced other symptoms compatible with CFP, including paradoxical temperature perception, paresthesias, numbness, arthralgia, and myalgia. No leftover fish was available from the meal.

Among the six CFP cases identified in this outbreak, patients ranged in age from 36 to 64 years (median $=48$ years), and four were male. The interval between consuming fish and symptom onset ranged from 3 to 7.25 hours (median $=3$ hours). All patients experienced paradoxical temperature perception, nausea, paresthesias, numbness, abdominal pain, diarrhea, arthralgias, and myalgias (Table). At the time of interview, all patients 


\begin{tabular}{|c|c|c|c|c|c|c|}
\hline \multirow[b]{2}{*}{ Characteristic } & \multicolumn{6}{|c|}{ Patient } \\
\hline & A & B & C & D & $\mathrm{E}$ & $\mathrm{F}$ \\
\hline $\begin{array}{l}\text { Date of fish } \\
\text { consumption }\end{array}$ & $\begin{array}{l}\text { 10/30/14 (lunch) } \\
\text { 10/30/14 (dinner) }\end{array}$ & $11 / 05 / 14$ & $11 / 05 / 14$ & $11 / 05 / 14$ & $11 / 05 / 14$ & $11 / 05 / 14$ \\
\hline $\begin{array}{l}\text { Type of fish } \\
\text { consumed }\end{array}$ & $\begin{array}{l}\text { Mahi-mahi (lunch) } \\
\text { Grouper filet (dinner) }\end{array}$ & Grouper heads & Grouper heads & Grouper heads & Grouper heads & Grouper heads \\
\hline $\begin{array}{l}\text { Source } \\
\text { of fish }\end{array}$ & $\begin{array}{l}\text { Restaurant A (lunch) } \\
\text { Restaurant B (dinner) }\end{array}$ & Grocery store A & Grocery store A & Grocery store A & Grocery store A & Grocery store A \\
\hline Food was shared & $\begin{array}{l}\text { No } \\
\text { No }\end{array}$ & Yes & Yes & Yes & Yes & Yes \\
\hline $\begin{array}{l}\text { Hours from fish } \\
\text { consumption to } \\
\text { symptom onset }\end{array}$ & $\begin{array}{c}7.25 \\
\text { (after dinner) }\end{array}$ & 3 & 3 & 3 & 3 & 3 \\
\hline \multicolumn{7}{|l|}{ Signs and symptoms } \\
\hline Nausea & $\mathrm{x}$ & $\mathrm{x}$ & $\mathrm{x}$ & $\mathrm{x}$ & $\mathrm{x}$ & $\mathrm{x}$ \\
\hline Vomiting & $\mathrm{x}$ & $\mathrm{x}$ & $x$ & $\mathrm{x}$ & $x$ & $x$ \\
\hline Abdominal pain & $\mathrm{x}$ & $\mathrm{x}$ & $x$ & $\mathrm{x}$ & $x$ & $\mathrm{x}$ \\
\hline Diarrhea & $\mathrm{x}$ & $\mathrm{x}$ & $\mathrm{x}$ & $x$ & $\mathrm{x}$ & $\mathrm{x}$ \\
\hline Myalgia & $\mathrm{x}$ & $x$ & $\mathrm{x}$ & $x$ & $x$ & $x$ \\
\hline Arthralgia & $\mathrm{x}$ & $\mathrm{x}$ & $\mathrm{x}$ & $\mathrm{x}$ & $\mathrm{x}$ & $\mathrm{x}$ \\
\hline Paresthesias & $\mathrm{x}$ & $\mathrm{x}$ & $\mathrm{x}$ & $\mathrm{x}$ & $\mathrm{x}$ & $\mathrm{x}$ \\
\hline $\begin{array}{l}\text { Numbness } \\
\text { Metallic taste }\end{array}$ & $\begin{array}{l}x \\
x\end{array}$ & $x$ & $x$ & $x$ & $x$ & $\mathrm{x}$ \\
\hline PTP & $x$ & $x$ & $x$ & $\mathrm{x}$ & $\mathrm{x}$ & $\mathrm{x}$ \\
\hline Dizziness & $x$ & & & & & \\
\hline Fever & $\mathrm{x}$ & & & & & \\
\hline $\begin{array}{l}\text { Type of medical } \\
\text { attention sought }\end{array}$ & Hotel physician & Hospital ED & Hospital ED & Hospital ED & Hospital ED & None \\
\hline Treatment & Supportive & None & None & None & None & - \\
\hline Initial diagnosis & None & Gastroenteritis & Gastroenteritis & Gastroenteritis & Gastroenteritis & - \\
\hline $\begin{array}{l}\text { How case was } \\
\text { identified }\end{array}$ & $\begin{array}{l}\text { DOH online foodborne } \\
\text { illness complaint system } \\
\text { (self-report) }\end{array}$ & $\begin{array}{l}\text { ESSENCE-FL } \\
\text { e-mail alert }\end{array}$ & $\begin{array}{l}\text { ESSENCE-FL } \\
\text { e-mail alert }\end{array}$ & $\begin{array}{l}\text { ESSENCE-FL } \\
\text { e-mail alert }\end{array}$ & $\begin{array}{l}\text { ESSENCE-FL } \\
\text { e-mail alert }\end{array}$ & $\begin{array}{l}\text { During interview of } \\
\text { patients B-E }\end{array}$ \\
\hline Date reported & $11 / 03 / 14$ & $11 / 06 / 14$ & $11 / 06 / 14$ & $11 / 06 / 14$ & $11 / 07 / 14$ & $11 / 07 / 14$ \\
\hline
\end{tabular}

Abbreviations: $\mathrm{DOH}=$ Florida Department of Health; ED = emergency department; ESSENCE-FL = Electronic Surveillance System for the Early Notification of Community-Based Epidemics-Florida; PTP = paradoxical temperature perception.

were still symptomatic, with neurologic symptoms being most severe. Medical care was sought, and supportive care provided to five patients; however, no patients received intravenous mannitol, which has been reported to be effective in reversing the symptoms of CFP, particularly in severe cases $(2,3)$.

Inspection of restaurant $A$, restaurant $B$, and grocery store $A$ revealed that restaurant $B$ and grocery store $A$ had obtained the grouper from supplier A. Fish consumed by patient $A$ at restaurant $A$ was ruled out as the potential intoxicant vehicle because it is not commonly associated with ciguatoxin cases and was dissimilar to the other case exposures. An inspection of the facilities of supplier A found that the implicated lot of fish was received whole and then divided into filets that were provided to restaurant $\mathrm{B}$ and fish heads to grocery store A. Subsequent joint efforts by DOH-Orange, DBPR, DACS, and FDA traced the fish consumed by all persons who became ill to two distributors, through supplier A. The black grouper appears to have originated from Mexico. It was not possible to determine whether the implicated filet and any of the fish heads came from the same fish.

No leftover fish from the meals that caused the illnesses was available for laboratory analysis. Black grouper fish heads from the same lot that patients B-F consumed were collected from grocery store A. Testing by FDA did not detect ciguatoxin.

\section{Discussion}

No FDA-cleared or approved clinical tests for CFP are currently available. $\mathrm{DOH}$ defines a case of $\mathrm{CFP}$ as the occurrence of CFP-compatible symptoms (e.g., paradoxical temperature perception and paresthesia) in a person within 24 hours after ingestion of fish. Detection of ciguatoxin in the meal remnants is strongly suggestive of CFP but is not required for case confirmation.

This investigation made use of multiple surveillance systems and an online consumer complaint system to identify six persons with histories of fish consumption and signs and symptoms consistent with CFP, after eating black grouper, 


\section{Summary}

What is already known on this topic?

Ciguatera fish poisoning (CFP), caused by the ingestion of predatory reef-dwelling fish harboring ciguatoxins is one of the most commonly reported fish-associated marine intoxications. Ciguatoxin retains toxicity regardless of freezing or cooking. Prompt treatment can reduce debilitating neurologic symptoms that are associated with CFP.

What is added by this report?

Syndromic surveillance systems in Florida identified six adults with CFP following consumption of black grouper. Five patients sought medical attention; health care providers did not make a diagnosis of CFP or report the cases to public health authorities, and none of the patients received treatment. Close collaboration among several investigating agencies allowed traceback efforts to link black grouper consumed by all patients to a common international distributor.

What are the implications for public health practice?

Syndromic surveillance systems capable of detecting CFP are essential public health tools to identify outbreaks and enhance investigations. Medical and public health practitioners should be educated to inquire about recent fish consumption when evaluating patients with clinically compatible signs and symptoms to allow for prompt treatment, and report suspected CFP cases to public health authorities to facilitate source-food traceback efforts. Public education on avoidance of consumption of relatively large predatory reef fish species known to be from ciguatoxic-endemic areas might reduce the risk for CFP.

a species known to harbor ciguatoxin. Although CFP is a reportable disease in Florida, none of the five patients who sought medical care received a diagnosis of CFP, nor was suspected CFP reported to DOH by health care providers. The outbreak traceback investigation identified that the fish sold to the patients was purchased from two retail establishments (i.e., restaurant $B$ and grocery store $A$ ) that received the fish from a common shipment to a single supplier through two distributors. Failure to detect ciguatoxin in FDA-tested fish heads samples taken from the same lot that intoxicated patients B-F is not inconsistent with the sporadic nature of the disease occurrence, or the observation that not all fish of a given species or from a given location are toxic (2). For these reasons, food recalls are likely to be inefficient public health tools in response to CFP outbreaks.
During 2012-2014, a total of 137 CFP cases were reported in Florida, $109(80 \%)$ of which were initially identified by surveillance and consumer complaint systems, 19 (14\%) were reported by health care providers, and nine $(7 \%)$ were reported via other, nondescribed methods. A health care provider diagnosis of CFP was documented for 73 (53\%) cases. Although the early gastrointestinal symptoms associated with CFP are nonspecific, health care providers need to be educated to consider the diagnosis of CFP in patients with a clinically compatible illness and a history of fish consumption, to facilitate administration of ameliorative therapy and timely reporting to public health officials $(3,4)$. Despite the fact that five of the six patients described in this report saw a health care provider, and at least four reported that they had eaten fish before becoming ill, the cases were only detected by DOH-Orange through an online self-reporting consumer complaint system and a syndromic surveillance system. Outbreak identification and associated public health efforts allowed for the education of the patients about CFP and the gathering of distribution and harvest data on the implicated fish. Avoiding consumption of large predatory reef fish from ciguatoxic-endemic areas, particularly the organs of these fish, which concentrate the toxin, can reduce the risk for CFP.

\section{Acknowledgments}

Lea Williams, Tiery Osias, DDS, Jamie DeMent, MNS, Florida Department of Health; Florida Department of Business and Professional Regulation; Florida Department of Agriculture and Consumer Services; US Food and Drug Administration.

\footnotetext{
${ }^{1}$ Florida Department of Health in Orange County; ${ }^{2}$ Florida Department of Health. Corresponding author: Benjamin G. Klekamp, ben.klekamp@flhealth.gov, 407-858-1400.
}

\section{References}

1. CDC. Marine toxins. Available at http://www.cdc.gov/nczved/divisions/ $\mathrm{dfbmd} /$ diseases/marine_toxins.

2. Schlundt J. Seafood poisoning. In: Control of communicable diseases manual. Heymann DL, ed. Washington, DC: American Public Health Association; 2015:223-4.

3. Palafox NA, Jain LG, Pinano AZ, Gulick TM, Williams RK, Schatz IJ. Successful treatment of ciguatera fish poisoning with intravenous mannitol. JAMA 1988;259:2740-2.

4. Pennotti R, Scallan E, Backer L, Thomas J, Angulo FJ. Ciguatera and scombroid fish poisoning in the United States. Foodborne Pathog Dis 2013;10:1059-66. 


\title{
State and Territorial Ebola Screening, Monitoring, and Movement Policy Statements - United States, August 31, 2015
}

\author{
Gregory Sunshine, JD ${ }^{1}$; Dawn Pepin, JD ${ }^{1}$; Marty Cetron, MD²; Matthew Penn, JD ${ }^{1}$
}

The 2014-2015 Ebola virus disease (Ebola) outbreak in West Africa is the largest in history, and as of October 4, 2015, had claimed 11,297 lives in Guinea, Liberia, and Sierra Leone (1). On August 7, 2014, CDC first posted guidance on monitoring and movement of persons who might have been exposed to Ebola virus to prevent the spread of Ebola into the United States. Since that time, the Interim U.S. Guidance for Monitoring and Movement of Persons with Potential Ebola Virus Exposure (2) has been regularly updated based on the latest information available, most recently on May 13, 2015. On October 11, 2014, after the first case of Ebola was diagnosed in the United States, entry screening was implemented in five U.S. airports to identify travelers from countries with widespread Ebola transmission who might have been exposed to Ebola during the days before arrival or who had signs or symptoms of Ebola at the time of arrival (3).

On October 24, 2014, New York and New Jersey, both home to airports conducting entry screening, announced monitoring and movement policies for incoming travelers returning from Ebola-affected countries (4). The New York and New Jersey policies included mandatory quarantine for any person who had direct contact with a person with Ebola while in one of the Ebola-affected countries, including any medical personnel who had provided medical services for persons infected with Ebola, as well as active monitoring and possible quarantine for all persons with travel history to the affected countries, including those who had no direct contact with an infected person (4).

On October 27, 2014, CDC guidance was updated by establishing a "low (but not zero) risk" category; adding a "no identifiable risk" category; modifying the recommended public health actions in the high, some, and low (but not zero) risk categories; and adding recommendations for specific groups and settings (2). Unlike the policies announced by New York and New Jersey, CDC guidance did not recommend mandatory quarantine. Instead, CDC guidance recommended active monitoring or direct active monitoring, and certain travel restrictions for symptomatic and some asymptomatic persons (2). Within a few months after issuance of the updated CDC guidance in October 2014, states began announcing state-specific monitoring and movement policies or amending existing policies. Some of these policies included stricter requirements than those recommended in CDC's guidance. Because of concerns about the potential impact of inconsistencies between state and federal monitoring and movement policies, CDC's Public Health
Law Program* assessed jurisdictional differences in guidance by systematically reviewing and evaluating publically available official Ebola screening, monitoring, and movement policies for each state and territory. These policies included executive orders, health orders, press releases, informational websites, and frequently asked questions (FAQ) resources. Each published policy was compared with CDC guidance to determine whether it was more or less restrictive than CDC guidance, equivalent to CDC guidance, unclear, or if no policy was publically available. Only policies contained on official government websites were examined, and the implementation of policies was not assessed.

Policies that require more extensive movement restrictions or more frequent reporting were considered more restrictive than CDC guidance, as were those that would place the traveler into a higher risk category than would CDC guidance. Policies that mirror CDC recommendations, or those that state that the jurisdiction follows CDC guidance, with no further articulation as to how that state's monitoring and movement policies were being implemented, were considered equivalent to CDC guidance. Policies were considered less restrictive than $\mathrm{CDC}$ recommendations if they require asymptomatic persons to undergo public health actions that are less stringent than CDC's recommendations, such as permitting all travelers from Ebola-affected countries to return to work regardless of risk level. Policies were considered to be unclear if they were ambiguous regarding the categorization, monitoring, and movement of persons, including policies that state that movement restrictions would be implemented on a case-by-case basis, or that link to CDC guidance, without indicating whether the jurisdiction was following this guidance, or simply providing the resource for informational purposes. If no policy could be found on any publically available websites managed by government authorities, that state or territory was considered to have no published policy.

As of August 31, 2015, a total of 17 states and the District of Columbia had policies that were more restrictive than current $\mathrm{CDC}$ guidance, 35 states and territories had policies that were equivalent to $\mathrm{CDC}$ guidance, no states or territories had policies that were less restrictive than CDC guidance, one territory had an unclear policy, and two territories did not have a publicly available monitoring and movement policy (Figure). ${ }^{\dagger}$

\footnotetext{
* CDC's Public Health Law Program works to advance the use of law as a public health tool through legal epidemiology and workforce development and by creating resources to improve understanding of law and policy decision-making for CDC programs and state, tribal, local, and territorial professionals.

$\dagger$ Additional information available at http://www.cdc.gov/phlp/docs/interimebolascreening.pdf.
} 
FIGURE. Ebola screening and monitoring policies for asymptomatic persons, by restrictiveness relative to CDC policy - United States, August 31, 2015

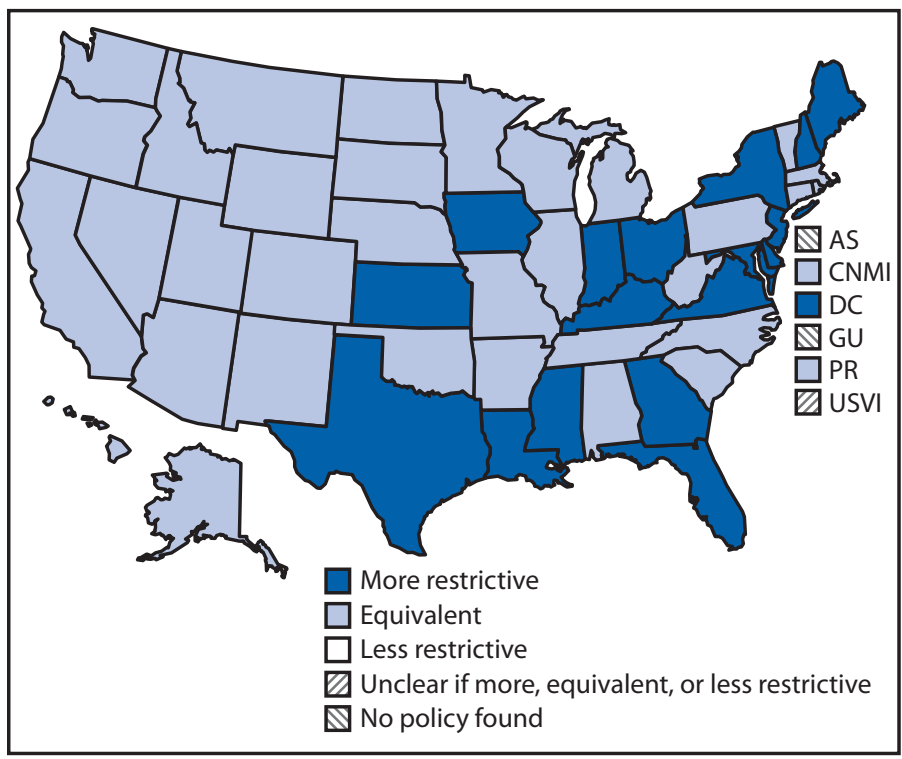

Abbreviations: $\mathrm{AS}=$ American Samoa; $\mathrm{CNMI}=$ Commonwealth of the Northern Mariana Islands; DC = District of Columbia; $G U=$ Guam; PR = Puerto Rico; $\mathrm{USVI}=$ U.S. Virgin Islands.

The results were published online as the Interim Table of State Ebola Screening and Monitoring Policies for Asymptomatic Individuals (5). Although states have the prerogative to set their own public health policies under the police powers reserved to them by the 10th Amendment of the U.S. Constitution $(\sigma)$, the differences in policies have the potential to create confusion among members of the public, persons considering whether to join the response effort, and responders returning from West Africa (7). Confusion can be minimized when states make their policies clear and readily accessible to the public.

\section{Acknowledgments}

Office for State, Tribal, Local, and Territorial Support, Public Health Law Program, CDC; Office of the Associate Director for Policy, CDC; Deployment Risk Mitigation Unit, CDC; Global Migration Task Force, CDC; State Coordination Task Force, CDC; Joint Information Center, CDC; Office for State, Tribal, Local, and Territorial Support, Program Planning, and Communication Unit, CDC.

${ }^{1}$ Office for State, Tribal, Local, and Territorial Support, Public Health Law Program, CDC; ${ }^{2}$ Division of Global Migration and Quarantine, National Center for Emerging and Zoonotic Infectious Diseases, CDC.

Corresponding author: Gregory Sunshine, gsunshine@cdc.gov, 404-498-0457.

\section{References}

1. CDC. 2014 Ebola outbreak in West Africa: case counts. Atlanta, GA: US Department of Health and Human Services, CDC; 2015. Available at http:// www.cdc.gov/vhf/ebola/outbreaks/2014-west-africa/case-counts.html.

2. CDC. Interim U.S. guidance for monitoring and movement of persons with potential Ebola virus exposure. Atlanta, GA: US Department of Health and Human Services, CDC; 2014. Available at http://www.cdc. gov/vhf/ebola/exposure/monitoring-and-movement-of-persons-withexposure.html.

3. Brown CM, Aranas AE, Benenson GA, et al. Airport exit and entry screening for Ebola—August-November 10, 2014. MMWR Morb Mortal Wkly Rep 2014;63:1163-7.

4. Governor's Press Office (New York State). Governor Andrew Cuomo and Governor Chris Christie announce additional screening protocols for Ebola at JFK and Newark Liberty International airports. October 24, 2014. Available at https://www.governor.ny.gov/news/governor-andrewcuomo-and-governor-chris-christie-announce-additional-screeningprotocols-ebola.

5. CDC. State Ebola protocols. Atlanta, GA: US Department of Health and Human Services, CDC; 2015. Available at http://www.cdc.gov/phlp/ publications/topic/ebola.html.

6. Jacobson v. Massachusetts, 197 U.S. 11 (1905). Available at http://caselaw. findlaw.com/us-supreme-court/197/11.html.

7. Shah R. Combating Ebola in West Africa: the international response. Testimony before the House Committee on Foreign Affairs, 113th Congress, 2nd Session. November 13, 2014. Available at http://www.gpo.gov/fdsys/ pkg/CHRG-113hhrg91450/html/CHRG-113hhrg91450.htm. 


\title{
Human Papillomavirus Vaccination Coverage Among School Girls in a Demonstration Project — Botswana, 2013
}

\author{
Mmakgomo Mimi Raesima, MD ${ }^{1}$; Sara E. Forhan, MD²; Andrew C. Voetsch, PhD²; Shannon Hewitt ${ }^{3}$; Susan Hariri, PhD ${ }^{4}$; Susan A. Wang, MD \\ Andrew R. Pelletier, MD²; Mpho Letebele, MD²; Tlhomamo Pheto ${ }^{1}$; Doreen Ramogola-Masire, MD ${ }^{6,7}$; Shenaaz El-Halabi, MPH ${ }^{1}$
}

Cervical cancer, caused by human papillomavirus (HPV), is the leading cause of cancer mortality among women in Botswana (1). Three vaccines prevent infection with HPV types responsible for the majority of cervical cancer worldwide. Two of these vaccines also protect against types that cause anogenital warts. Two vaccines are currently prequalified by the World Health Organization (WHO); these were $>90 \%$ efficacious in preventing precancerous lesions caused by HPV types 16 and 18 (the cause of $70 \%$ of cervical cancers) in clinical trials studying women who received the recommended 3-dose series before exposure to targeted HPV types. WHO recommends targeting HPV vaccination to girls aged 9-13, before initiation of sexual activity and thus HPV exposure (2). This report summarizes HPV vaccination coverage among girls aged $\geq 9$ years enrolled in grades $4-6$ in 23 primary schools in Molepolole, Botswana, during a 2013 HPV vaccination demonstration project conducted by the Botswana Ministry of Health (MOH). Of the 2,488 eligible school girls, 83\% received the first dose and $79 \%$ completed the 3 -dose HPV vaccination series. Drop out between first and third dose was 5\%. No serious adverse events were reported. Given the successful pilot, the project was expanded to immunize approximately 6,000 girls in 2014, followed by national rollout of the HPV vaccine in 2015.

Botswana is an upper middle income country with a population of 2 million in southern Africa. Approximately 22,000 females are born annually. Human immunodeficiency virus (HIV) prevalence among women aged 15-49 years is 28\%.* Cervical cancer, the fourth most common cancer worldwide (3), is the most common cancer among women aged 15-44 years and the leading cause of cancer mortality among women in Botswana, reflecting the 4-5 times increased risk for cervical cancer among HIV-infected women (3). Primary prevention of cervical cancer via HPV vaccination might be particularly beneficial to Botswana, given the country's challenges with both HIV infection and cervical cancer. However, establishing a sustainable program to deliver HPV vaccine to a population not previously targeted for immunizations can be challenging in resource-limited countries.

\footnotetext{
* Statistics Botswana. Preliminary results Botswana acquired immune deficiency syndrome (AIDS) indicator survey IV (BAIS IV), 2013: stats brief. Gaborone, Botswana: Central Statistics Office, Ministry of Finance and Development Planning; 2013. Available at http://www.cso.gov.bw/templates/cso/file/File/ BAIS\%20IV\%20PRELIMINARY\%20RESULTS\%20Nov\%202013(1).pdf.
}

In 2012, the Botswana $\mathrm{MOH}$ initiated its National Cervical Cancer Prevention Program Comprehensive Strategy (2012-2016). The same year, the Pink Ribbon Red Ribbon (PRRR) initiative, a public-private partnership for breast and cervical cancer prevention and treatment, was implemented to expand cervical cancer screening and treatment with a focus on HPV-related disease. With PRRR and other donor support, the Botswana MOH decided to conduct a grade-based HPV vaccination demonstration project in primary schools. The project was completed during the 2013 school year (JanuaryDecember) in Molepolole, a town with a population of 63,000 located 31 miles (50 kilometers) from the national capital. The objectives were to evaluate HPV vaccine implementation among age-eligible girls enrolled in school and to improve planning for possible expansion of HPV vaccine activities.

A multidisciplinary team, with representatives from the Botswana $\mathrm{MOH}$, including Expanded Program on Immunization, Ministry of Education, WHO, nongovernmental organizations, and other key stakeholders, developed the project protocol, educational materials, a parental consent form, and data-gathering tools. The Botswana $\mathrm{MOH}$ determined the project to be public health practice. Multiple educational meetings for community stakeholders, sensitization meetings for parents and educators, and training sessions for local public health providers participating in the project were held before implementation. All girls aged $\geq 9$ years attending grades 4-6 at any of Molepolole's 17 public primary schools, five private primary schools, or one school for special needs students, and who had written parental consent, were eligible for vaccination. Participating schools provided enrollment lists of female students. The quadrivalent HPV vaccine, Gardasil (Merck and Co.), was administered in schools by public health workers in March, May (approximately 2 months after the first dose), and early October 2013 (approximately 6 months after the first dose). Immunization teams visited each school twice during each of the three vaccination campaign rounds. Girls who missed a dose at school could receive it at Scottish Livingston Hospital in Molepolole. Vaccination data on each girl were collected on paper-based records and transferred to a spreadsheet. To identify the number of girls who received HPV vaccination during March-December 2013, staff reviewed the line lists of girls by school, which contained birthdate, grade, documentation of parental consent, and HPV vaccination date. 
There were 2,742 girls registered in grades $4-6$ in the 23 participating schools (median enrollment $=135$ girls; range $=12-227$ girls). Of the 2,590 (94\%) girls with a recorded date of birth, 2,488 (96\%) were aged $\geq 9$ years on the first day of school vaccination in March 2013. Among these girls, $83 \%(\mathrm{n}=2,075)$ received the first dose, $82 \%(\mathrm{n}=2,049)$ received 2 doses, and $79 \%(\mathrm{n}=1,967)$ completed the 3 -dose series (Table). Overall vaccination completion among girls who received the first dose was $95 \%$. Approximately one fifth (431/2488) of girls with known date of birth were without documented parental consent, 88 of whom received vaccination. The proportion of school girls vaccinated increased with increasing age (Cochran-Armitage trend test $\mathrm{p}<0.001)$ and was higher among girls who attended public school compared with those who attended private school $(\mathrm{p}<0.001)$. Passive surveillance for adverse events (following girls for 30 days postimmunization) was designed for this campaign. No serious adverse events were reported.

\section{Discussion}

HPV vaccines are safe and highly efficacious (4); postlicensure monitoring data from countries with high vaccination coverage indicate population-level impact against early cervical disease caused by targeted HPV types, further supporting these results (5). The vaccines' potential impact is likely to be greatest in countries with less established cervical cancer screening programs and high disease levels, such as Botswana; however, delivering a multidose vaccine to adolescent girls is challenging and has impeded large scale introduction in lowresource countries.

The 79\% 3-dose vaccination coverage achieved in this project is comparable to that attained in an HPV vaccination project conducted in the Mwanza Region, Tanzania (76.1\%), but lower than the vaccination coverage in school-based demonstration projects in KwaZulu Natal province, South Africa $(97.8 \%)(6,7)$. Approximately all doses were administered on time and at schools. Similar to the Tanzania demonstration project, the vaccination rate was higher in public than in private schools (6).

The findings in this report are subject to limitations. Out-ofschool preadolescent girls were not represented in the estimated vaccination coverage; thus vaccination coverage is likely overestimated for the general population of girls aged 9-13 years. WHO recommends use of population-based data to identify all eligible girls in the population by year of age. ${ }^{\dagger}$ In this project, the number of out-of-school girls in the Molepolole catchment

\footnotetext{
${ }^{\dagger}$ World Health Organization. Report of the HPV vaccine delivery meeting: identifying needs for implementation and research. Geneva, Switzerland: World Health Organization; 2012. Available at http://www.who.int/immunization/ documents/WHO_IVB_12.09.
}

TABLE. Total number and percentages of female students who received human papillomavirus vaccine, by age, grade, and school type - Molepolole, Botswana, 2013

\begin{tabular}{|c|c|c|c|c|c|c|c|}
\hline \multirow[b]{2}{*}{ Characteristic } & \multirow{2}{*}{$\begin{array}{c}\text { No. } \\
\text { eligible }\end{array}$} & \multicolumn{2}{|c|}{$\geq 1$ dose } & \multicolumn{2}{|c|}{$\geq 2$ doses } & \multicolumn{2}{|c|}{3 doses } \\
\hline & & No. & (\%) & No. & (\%) & No. & (\%) \\
\hline \multicolumn{8}{|l|}{ Age (yrs)* } \\
\hline 9 & 576 & 455 & (79) & 447 & (78) & 432 & (75) \\
\hline 10 & 766 & 636 & (83) & 632 & (83) & 610 & (80) \\
\hline 11 & 682 & 580 & (85) & 571 & (84) & 546 & (80) \\
\hline 12 & 319 & 276 & (87) & 273 & (86) & 262 & (82) \\
\hline 13 & 94 & 85 & (90) & 84 & (89) & 79 & (84) \\
\hline $14+$ & 51 & 43 & (84) & 42 & (82) & 38 & (75) \\
\hline \multicolumn{8}{|l|}{ Grade } \\
\hline 4 & 691 & 567 & (82) & 559 & (81) & 540 & (78) \\
\hline 5 & 813 & 684 & (84) & 679 & (84) & 658 & (81) \\
\hline 6 & 849 & 755 & (89) & 745 & (88) & 715 & (84) \\
\hline Special needs & 39 & 36 & (92) & 36 & (92) & 29 & (74) \\
\hline Missing grade & 96 & 33 & (34) & 30 & (31) & 25 & (26) \\
\hline \multicolumn{8}{|l|}{ School type } \\
\hline Public & 2,322 & 1,956 & (84) & 1,930 & (83) & 1,858 & (80) \\
\hline Private & 166 & 119 & (72) & 119 & (72) & 109 & (66) \\
\hline Total & 2,488 & 2,075 & (83) & 2,049 & (82) & 1,967 & (79) \\
\hline
\end{tabular}

* Age on date of first vaccination day in school.

area was not available. However, an estimated $15 \%$ of primary school-aged girls were out-of-school in Botswana in 2009 (8). Vaccination coverage might have been underestimated because of incomplete documentation of doses administered at Scottish Livingston Hospital, or because the analysis excluded girls without recorded birthdates who were immunized. The scalability and sustainability of the HPV vaccination strategy used in this demonstration project were not assessed.

Programmatic challenges and expense of the 3-dose HPV vaccination series led to global interest in a 2 -dose $H P V$ vaccine schedule (0, 6-12 months). By using data from noninferiority immunogenicity trials and postlicensure studies of both vaccines, in April 2014, WHO recommended a 2-dose schedule for immunization of immunocompetent girls aged 9-14 years for either vaccine at 0,6 - or 0,12 -month intervals (2). The full 3 -dose series remains recommended for girls aged $\geq 15$ years, for those who are immunocompromised, or whenever interval between the first 2 doses is $<6$ months.

Demonstration projects are valuable to identify and address challenges, build necessary partnerships across government agencies and with other stakeholders, and gauge political support before implementing a national vaccination program. Although Botswana's demonstration project successfully achieved high vaccination coverage among girls enrolled in school, problems with implementation occurred. At campaign initiation, certain grade 4 girls were aged $<9$ years, precluding complete vaccination of grade 4 girls through this project. Required signed parental consent, a nonstandard practice for Botswana's immunization program, likely created confusion that resulted in 1) vaccination of certain girls who lacked 


\section{Summary}

What is already known on this topic?

Human papillomavirus (HPV) infection is common and aggressive in persons infected with human immunodeficiency virus (HIV). With an HIV prevalence of $28 \%$ among females aged 15-49, cervical cancer is the leading cause of cancer death among women in Botswana. Before 2013, HPV vaccine had not been used in the public sector in Botswana.

What is added by this report?

Efforts to expand services for cervical cancer through the Pink Ribbon Red Ribbon initiative focused on HPV-related disease in Botswana. A demonstration project for HPV vaccination was developed by the Ministry of Health for school girls aged $\geq 9$ years in primary schools in one community. A total of 1,967 (79\%) of 2,488 eligible girls received 3 doses of vaccine in the immunization effort that was centered in schools.

What are the implications for public health practice?

Preventing HPV infection in girls is an important component of a national comprehensive cervical cancer control program. $\mathrm{HPV}$ vaccination programming is challenging, and demonstration projects can prepare countries for national introduction. The success of the initial HPV vaccination effort in Botswana led to an expanded project in 2014, with implementation of nationwide rollout of the HPV vaccine in 2015. It might be beneficial for future HPV vaccination campaigns to include strategies to reach out-of-school girls.

signed consents, and 2) lower vaccination rates, despite robust precampaign community sensitization efforts. On the basis of the 2013 challenges, Botswana's $2014 \mathrm{HPV}$ vaccination project was modified to target grades 5-7 and replaced formal written consent with an implied consent process (9).

The national HPV vaccine rollout in 2015 employed a 2-dose vaccination schedule. Recent post hoc analysis of data from two large vaccine trials reported that women aged $15-25$ years who received a single dose of HPV vaccine were protected against HPV types 16 and 18 for 4 years after vaccination (10). In Botswana, concerns still being discussed include how best to provide vaccinations to out-of-school girls; the best venue for delivering vaccine (school versus health care facility); and how to provide a third dose to girls who are HIV-infected (HIV prevalence among girls aged $10-14$ years is $4.4 \%$ in Botswana), aged $\geq 15$ years, or received the first 2 doses $<6$ months apart.

\section{Acknowledgments}

Botswana Ministry of Health HPV Immunization Working Group, Gaborone, Botswana; public health workers in Molepolole, Botswana.

\footnotetext{
${ }^{1}$ Botswana Ministry of Health; ${ }^{2}$ Division of Global HIV/AIDS, Center for Global Health, CDC; ${ }^{3}$ United States Peace Corps; ${ }^{4}$ Division of STD Prevention, National Center for HIV/AIDS, Viral Hepatitis, STD, and TB Prevention, CDC; ${ }^{5}$ Global Immunization Division, Center for Global Health, CDC; ${ }^{6}$ Botswana-University of Pennsylvania Partnership; ${ }^{7}$ Department of Medicine, University of Botswana.

Corresponding author: Sara Forhan, ggt1@cdc.gov, 404-639-0374.
}

\section{References}

1. Bruni L, Barrionuevo-Rosas L, Albero G, et al. Human papillomavirus and related diseases in Botswana. Summary report 2015-03-20. Barcelona, Spain: Institut Català d'Oncologia Information Centre on HPV and Cancer; 2015. Available at http://www.hpvcentre.net/statistics/ reports/BWA.pdf.

2. World Health Organization. Human papillomavirus vaccines: WHO position paper, October 2014. Wkly Epidemiol Rec 2014;89:465-91. Available at http://www.who.int/immunization/diseases/hpv/wer8943.pdf.

3. International Agency for Research on Cancer. GLOBOCAN 2012: estimated cancer incidence, mortality and prevalence worldwide in 2012. Lyon, France: International Agency for Research on Cancer, World Health Organization; 2012. Available at http://globocan.iarc.fr.

4. Schiller JT, Castellsagué X, Garland SM. A review of clinical trials of human papillomavirus prophylactic vaccines. Vaccine 2012;30(Suppl 5): F123-38.

5. Hariri S, Markowitz LE, Dunne EF, Unger ER. Population impact of HPV vaccines: summary of early evidence. J Adolesc Health 2013;53:679-82.

6. Watson-Jones D, Baisley K, Ponsiano R, et al. Human papillomavirus vaccination in Tanzanian schoolgirls: cluster-randomized trial comparing 2 vaccine-delivery strategies. J Infect Dis 2012;206:678-86.

7. Moodley I, Tathiah N, Mubaiwa V, Denny L. High uptake of Gardasil vaccine among 9-12-year-old schoolgirls participating in an HPV vaccination demonstration project in KwaZulu-Natal, South Africa. S Afr Med J 2013;103:318-21.

8. United Nations Educational, Scientific, and Cultural Organization (UNESCO) Institute for Statistics Education (UIS). MetaData: number of out-of-school children of primary school age. Montreal, Canada: UIS, UNESCO; 2015. Available at http://data.uis.unesco.org/Index. aspx?queryid $=121$.

9. World Health Organization. Considerations regarding consent in vaccinating children and adolescents between 6 and 17 years old. Geneva, Switzerland: World Health Organization; 2014. Available at http://www. who.int/immunization/programmes_systems/policies_strategies/ consent_note.

10. Kreimer AR, Struyf F, Del Rosario-Raymundo MR, et al.; Costa Rica Vaccine Trial and PATRICIA study groups. Efficacy of fewer than three doses of an HPV-16/18 AS04-adjuvanted vaccine: combined analysis of data from the Costa Rica Vaccine and PATRICIA trials. Lancet Oncol 2015;16:775-86. 


\section{A Cluster of Ocular Syphilis Cases - Seattle, Washington, and San Francisco, California, 2014-2015}

Sophie Woolston, $\mathrm{MD}^{1}$; Stephanie E. Cohen, $\mathrm{MD}^{2,3}$; Robyn Neblett Fanfair, $\mathrm{MD}^{4}$; Sarah C. Lewis, $\mathrm{MD}^{3}$; Christina M. Marra, $\mathrm{MD}^{5}$; Matthew R. Golden, MD ${ }^{1,6}$

From December 1, 2014, to January 30, 2015, in King County, Washington, four cases of ocular syphilis, defined as clinical signs or symptoms consistent with ocular disease (e.g., uveitis or vision loss) in a person with laboratory-confirmed syphilis of any stage, were reported. All four cases occurred in men who have sex with men (MSM), two of whom were sex partners. Median age of the four patients was 39 years (range $=29-52$ years). Three of the patients were infected with human immunodeficiency virus (HIV). Among the three HIVinfected patients, the median CD4 count was 111 cells $/ \mathrm{ml}$, and the median HIV-RNA was 34,740 copies/ml. All four patients had visual symptoms, including vision loss, flashing lights, and blurry vision. Ophthalmologic examinations were performed and all four were diagnosed with uveitis. All four patients had positive serum from rapid plasma reagin $(\mathrm{RPR})$ testing (titer range $=1: 256-1: 4096)$. Based on history, one patient had late latent syphilis, and the remaining three received diagnoses of early latent syphilis. The three patients with early latent syphilis had cerebrospinal fluid (CSF) analysis performed; two had positive CSF in venereal disease research laboratory (VDRL) testing. Three patients received treatment with aqueous crystalline penicillin $\mathrm{G}$ for 14 days, and one was treated with 10 days of procaine penicillin and probenecid. All four patients had initial improvement in ocular symptoms after treatment. However, one patient still had a blind spot in one eye 1 month after treatment, and two patients were considered legally blind after 5 months; the fourth patient was lost to follow-up.

Public Health-Seattle \& King County has estimated that approximately $6-12$ cases of symptomatic ocular syphilis occur annually in the county (1). The occurrence of four cases within 2 months led to a clinical advisory to medical providers and west coast health departments.

Following the clinical advisory from King County, the San Francisco Department of Public Health identified eight cases of ocular syphilis reported from December 15, 2014, to March 25, 2015. Seven cases (88\%) were in males; six (75\%) were in MSM. No epidemiologic links were identified among the patients. Median age of the patients was 52 years (range $=35-58$ years). Seven $(88 \%)$ were HIV-infected (six MSM and one female commercial sex worker). Four patients had CD4 and HIV-RNA lab data available; median CD 4 count was 291 cells/ml, median HIV-RNA was 84,500 copies $/ \mathrm{ml}$. Ophthalmologic examinations were performed on all eight patients, and records were reviewed for five. Diagnoses included ischemic optic neuropathy, uveitis, and retinal detachment. All patients had positive serum RPR (titer range $=1: 256-1: 8192$ ); two had an initial false negative RPR because of the prozone effect. Three patients had a rash consistent with secondary syphilis, four had early latent syphilis, and one had late latent syphilis. Four cases had CSF analysis, three with a positive CSF VDRL result. All eight patients received aqueous crystalline penicillin $G$ for 14 days. Following treatment, seven patients had improvement in ocular symptoms, and one patient had permanent visual loss in one eye after 3 months.

Ocular syphilis, a clinical manifestation of neurosyphilis, typically occurs during early syphilis; uveitis is the most common presentation (2-4). For sexually active persons, the following steps can reduce the risk for syphilis: 1) being in a long-term mutually monogamous relationship with a partner who has been tested and has not tested positive for early syphilis; 2) using latex condoms correctly every time they have sex; and 3) for MSM, having annual screening for syphilis, and more frequent screening for MSM at greater risk. All patients who receive a diagnosis of syphilis should be asked screening questions to identify visual, hearing, or neurologic symptoms and receive a careful neurologic exam. Patients with ocular symptoms consistent with syphilis should be serologically evaluated for syphilis. An immediate ophthalmologic evaluation and CSF examination is recommended for patients with syphilis and ocular complaints. However, a normal CSF examination can occur with ocular syphilis. Ocular syphilis cases should be managed according to the treatment recommendations for neurosyphilis, regardless of CSF results, and patients should be tested for HIV (5).

Cases of ocular syphilis should be reported to the state or local health department within 24 hours of diagnosis (G). For questions about possible ocular syphilis cases please contact Sara E. Oliver, MD, at 404-639-1204 or at yxo4@cdc.gov.

\footnotetext{
${ }^{1}$ Department of Medicine, Division of Allergy and Infectious Diseases, University of Washington; ${ }^{2}$ San Francisco Department of Public Health; ${ }^{3}$ Division of Infectious Diseases, University of California, San Francisco; ${ }^{4}$ Division of STD Prevention, National Center for HIV/AIDS, Viral Hepatitis, STD, and TB Prevention, CDC; ${ }^{5}$ Department of Neurology, University of Washington; ${ }^{6}$ HIV/STD Control Program, Public Health - Seattle \& King County.

Corresponding author: Robyn Neblett Fanfair, 404-639-6044, iyo5@cdc.gov.
} 


\section{References}

1. Dombrowski JC, Pedersen R, Marra CM, Kerani RP, Golden MR. Complicated syphilis may be more common than previous estimates suggest. Presented at the 2014 STD Prevention Conference, Atlanta, GA; June 9-12, 2014

2. Li JZ, Tucker JD, Lobo AM, et al. Ocular syphilis among HIV-infected individuals. Clin Infect Dis 2010;51:468-71.

3. Moore JE. Syphilitic iritis. Am J Ophthalmol 1931;14:110-26.
4. Morthey LC, Skalicky SE, Gurbaxani A, McCluskey PJ. Syphilitic uveitis and optic neuritis in Sydney, Australia. Br J Ophthalmol 2015;99:1215-9.

5. Workowski KA, Bolan GA. Sexually transmitted diseases treatment guidelines, 2015. MMWR Recomm Rep 2015 (No. RR-3).

6. CDC. Clinical advisory: ocular syphilis in the United States. Atlanta, GA: US Department of Health and Human Services, CDC; 2015. Available at http://www.cdc.gov/std/syphilis/clinicaladvisoryos2015.htm. 


\section{National Teen Driver Safety Week - October 18-24, 2015}

During 2004-2013, the number of teens aged 13-19 years who died in motor vehicle crashes declined by $55 \%$ from 5,645 to 2,524 (1). During the same period, the rate of passenger vehicle drivers aged 16-19 years involved in fatal crashes decreased 56\%, from 34.7 to 15.1 per 100,000 persons (1). Despite these encouraging trends, motor vehicle crashes remain the leading cause of death for teens.

Graduated driver licensing (GDL) is widely credited with contributing to declines in teen crash fatalities. Evaluations of GDL have demonstrated a $20-40 \%$ reduction in crash risk for the youngest drivers (2). GDL provides longer practice periods, limits driving under high risk conditions for newly licensed drivers, and requires greater participation of parents in their teens' learning-to-drive process.

Research indicates that more comprehensive GDL systems prevent more fatal crashes compared with less comprehensive GDL systems (3-5). These systems include provisions, such as: a minimum age of 16 years for learners' permits; a mandatory holding period of at least 12 months for learners' permits; nighttime driving restrictions between 10:00 p.m. and
5:00 a.m. (or longer) for intermediate or provisional license holders; a limit of zero or one young passengers that can ride with intermediate or provisional license holders without adult supervision; and a minimum age of 18 years for full licensure. Additional information on National Teen Driver Safety Week available at http://www.trafficsafetymarketing.gov/teens. Additional information on safe teen driving available at http:// www.cdc.gov/MotorVehicleSafety/Teen_Drivers/teendrivers_factsheet.html and http://www.cdc.gov/parentsarethekey/index.html.

\section{References}

1. Insurance Institute for Highway Safety. Fatality facts 2013: teenagers. Arlington, VA: Insurance Institute for Highway Safety; 2013. Available at http://www.iihs.org/iihs/topics/t/teenagers/fatalityfacts/teenagers.

2. Shope JT. Graduated driver licensing: review of evaluation results since 2002. J Safety Res 2007;38:165-75.

3. Williams AF, Tefft BC, Grabowski JG. Graduated driver licensing research, 2010-present. J Safety Res 2012;43:195-203.

4. Mayhew D, Williams A, Pashley C. A new GDL framework: evidence base to integrate novice driver strategies. Ottawa, Canada: Traffic Injury Research Foundation; 2014.

5. CDC. Prevention Status Reports: Graduated Driver Licensing System 2013. Atlanta, GA: US Department of Health and Human Services, CDC; 2013. Available at http://www.cdc.gov/psr/motorvehicle/index. html\#graduated. 


\section{Errata}

\section{Vol. 64, No. 17}

In the report, "Vital Signs: Leading Causes of Death, Prevalence of Diseases and Risk Factors, and Use of Health Services Among Hispanics in the United States - 2009-2013, on page 476, two errors occurred in Table 5, "Annualized prevalence of lack of health insurance, nonutilization of medical care or prescription drugs, and use of preventive screening tests for cancer among adults, by sex, race/ethnicity, Hispanic/ Latino subpopulation, and nativity - United States, National Health Interview Survey (NHIS), 2011-2013, 2009-2013, or 2010 and 2013.*”

The heading for the sixth main column should read, "Use of colorectal tests or procedures (crude) ${ }^{\dagger \dagger}$ (50-75 yrs, 2010 and 2013)."

The heading for the seventh main column should read, "Use of mammography in the past 2 years among women (crude) $\$ \$$ (50-74 yrs, 2010 and 2013)."

\section{Vol. 64, No. 38}

In the report, "Ebola Virus Disease in Health Care Workers - Guinea, 2014," one of the author affiliations was incorrect. The affiliations should have read as follows: "1Division of Population Health, National Center for Chronic Disease Prevention and Health Promotion, CDC; ${ }^{2}$ Division of Global HIV/AIDS, Center for Global Health, CDC; ${ }^{3}$ Division of STD Prevention, National Center for HIV/AIDS, Viral Hepatitis, STD, and TB Prevention, CDC; ${ }^{4}$ Division of Global Health Protection, Center for Global Health, CDC; ${ }^{5}$ Guinea Ministry of Health and Public Hygiene; ${ }^{6}$ Division of Surveillance, Hazard Evaluations, and Field Studies, National Institute for Occupational Safety and Health, CDC; ${ }^{7}$ Division of Parasitic Diseases and Malaria, Center for Global Health, CDC; ${ }^{8}$ World Health Organization, Conakry, Guinea." 


\section{Vol. 64, No. 14}

In the report, "Poisoning Deaths Involving Opioid Analgesics — New York State, 2003-2012," multiple errors occurred.

On page 377, the third paragraph should read as follows: "From 2003 to 2012, the number of deaths with drug poisoning as an underlying cause increased from 1,382 to 1,876. During the same period, deaths involving opioid analgesics increased from 335 in 2003 to 883 in 2012 (Table). In addition, non-opioid analgesic drug poisonings that involved an unspecified drug, for which opioid analgesics might account partially, ranged from 204 deaths in 2010 to 294 in 2008 . Over this period, the percentage of drug deaths that involved opioid analgesics increased from $24.2 \%$ in 2003 to $47.1 \%$ in 2012 , reaching a high of $\mathbf{5 4 . 0 \%}$ in 2010."

The last two sentences of the fourth paragraph should read as follows: "Rate ratios (RRs) comparing death rates between 2003 and 2012 (Table) indicate that, despite having the lowest overall rates, the highest rate of increase in deaths involving opioid analgesics was among those under 15 years of age $(R R=3.7)$, followed by those 65-84 years of age $(R R=3.6)$. Whites, females, and those residing outside of NYC also showed higher rates of increase in opioid analgesic-related mortality $(R R=2.8,2.9$, and 3.9, respectively)."
The second sentence of the fifth paragraph should read as follows: "Deaths per 100,000 among all New York state residents not enrolled in Medicaid increased from 1.18 in 2003 to 2.82 in 2012, while among Medicaid enrollees, the rates increased from 3.48 in 2003 to 8.31 over the same period."

On page 379 , the last sentence of the first paragraph should read as follows: "Consistent with the national trend (5), the rate of increase, as indicated by the rate ratios, is slightly higher in New York state among women than among men ( $R R=2.9$ and 2.4, respectively)."

It is stated in several places in the report that rates of opioid analgesic-related mortality in New York state were consistently higher among residents who lived outside New York City (NYC). After correction of certain data, it was found that these rates were higher among those residing outside of NYC during 2007-2012, but the rates were lower among those residing outside of NYC during 2003-2006.

On page 378 , in the Table "Number and crude death rates for poisonings involving opioid analgesics, by year and demographic characteristics - New York state, 2003-2012," correction of certain data also resulted in numerous incorrect values. The corrected Table is as follows: 
TABLE. Number and crude death rates for poisonings involving opioid analgesics, by year and demographic characteristics — New York state, 2003-2012

\begin{tabular}{|c|c|c|c|c|c|c|c|c|c|c|c|}
\hline \multirow[b]{2}{*}{ Characteristic } & \multicolumn{10}{|c|}{ Year } & \multirow{2}{*}{$\frac{\text { Ratio }}{2012: 2003}$} \\
\hline & 2003 & 2004 & 2005 & 2006 & 2007 & 2008 & 2009 & 2010 & 2011 & 2012 & \\
\hline \multicolumn{12}{|l|}{ Number of deaths } \\
\hline All drug poisonings & 1,382 & 1,126 & 1,550 & 1,660 & 1,691 & 1,679 & 1,570 & 1,415 & 1,853 & 1,876 & 1.4 \\
\hline $\begin{array}{l}\text { Drug poisonings } \\
\text { involving opioid } \\
\text { analgesics }\end{array}$ & 335 & 295 & 487 & 655 & 698 & 769 & 737 & 764 & 909 & 883 & 2.6 \\
\hline \multicolumn{12}{|c|}{ Opioid analgesics-related deaths per 100,000 population } \\
\hline Total & 1.75 & 1.53 & 2.53 & 3.39 & 3.62 & 3.95 & 3.77 & 3.94 & 4.67 & 4.51 & 2.6 \\
\hline \multicolumn{12}{|l|}{ Age group (yrs) } \\
\hline$<15$ & 0.03 & 0.03 & 0.08 & 0.03 & 0.03 & 0.06 & 0.08 & 0.06 & 0.09 & 0.11 & 3.7 \\
\hline $15-19$ & 0.39 & 0.62 & 0.91 & 1.30 & 0.79 & 1.78 & 1.39 & 1.39 & 1.28 & 1.15 & 2.8 \\
\hline $20-44$ & 2.34 & 2.06 & 3.38 & 4.61 & 5.09 & 5.15 & 5.06 & 5.40 & 6.74 & 6.22 & 2.7 \\
\hline $45-64$ & 3.37 & 2.89 & 4.73 & 6.14 & 6.58 & 7.23 & 6.84 & 6.99 & 7.90 & 7.82 & 2.3 \\
\hline $65-84$ & 0.37 & 0.28 & 0.51 & 0.93 & 0.42 & 1.00 & 0.76 & 0.85 & 0.88 & 1.32 & 3.6 \\
\hline$\geq 85$ & 0.29 & 0.28 & 0.27 & 0.54 & 1.04 & 0.50 & 0.26 & 0.26 & 0.49 & 0.72 & 2.5 \\
\hline \multicolumn{12}{|l|}{ Sex } \\
\hline Females & 1.11 & 1.03 & 1.48 & 2.05 & 2.43 & 2.57 & 2.70 & 2.58 & 3.39 & 3.18 & 2.9 \\
\hline Males & 2.43 & 2.07 & 3.65 & 4.82 & 4.88 & 5.40 & 4.90 & 5.40 & 6.03 & 5.76 & 2.4 \\
\hline \multicolumn{12}{|l|}{ Race } \\
\hline Black & 1.39 & 1.24 & 2.20 & 2.46 & 2.06 & 1.78 & 2.13 & 2.21 & 2.36 & 2.48 & 1.8 \\
\hline White & 1.91 & 1.67 & 2.76 & 3.83 & 4.28 & 4.79 & 4.45 & 4.77 & 5.67 & 5.39 & 2.8 \\
\hline Other & 0.98 & 0.84 & 1.02 & 1.39 & 0.98 & 0.96 & 1.14 & 0.79 & 1.43 & 1.77 & 1.8 \\
\hline \multicolumn{12}{|l|}{ Region } \\
\hline NYC & 2.40 & 2.48 & 3.05 & 3.77 & 3.25 & 3.52 & 3.30 & 3.67 & 3.64 & 3.89 & 1.6 \\
\hline $\begin{array}{l}\text { New York state, } \\
\text { excluding NYC }\end{array}$ & 1.27 & 0.85 & 2.15 & 3.11 & 3.89 & 4.27 & 4.13 & 4.14 & 5.43 & 4.98 & 3.9 \\
\hline \multicolumn{12}{|l|}{ Medicaid status } \\
\hline Medicaid & 3.48 & 3.28 & 5.17 & 6.31 & 7.03 & 7.23 & 6.82 & 7.06 & 8.40 & 8.31 & 2.4 \\
\hline Non-Medicaid & 1.18 & 0.92 & 1.57 & 2.33 & 2.40 & 2.78 & 2.61 & 2.66 & 3.06 & 2.82 & 2.4 \\
\hline
\end{tabular}

Abbreviation: NYC = New York City. 


\section{Percentage* of Children Aged 5-17 Years with Diagnosed Attention Deficit/Hyperactivity Disorder (ADHD), ${ }^{\dagger}$ by Poverty Status ${ }^{\S}$ and Sex — National Health Interview Survey, ${ }^{\mathbb{2}}$ 2011-2014}

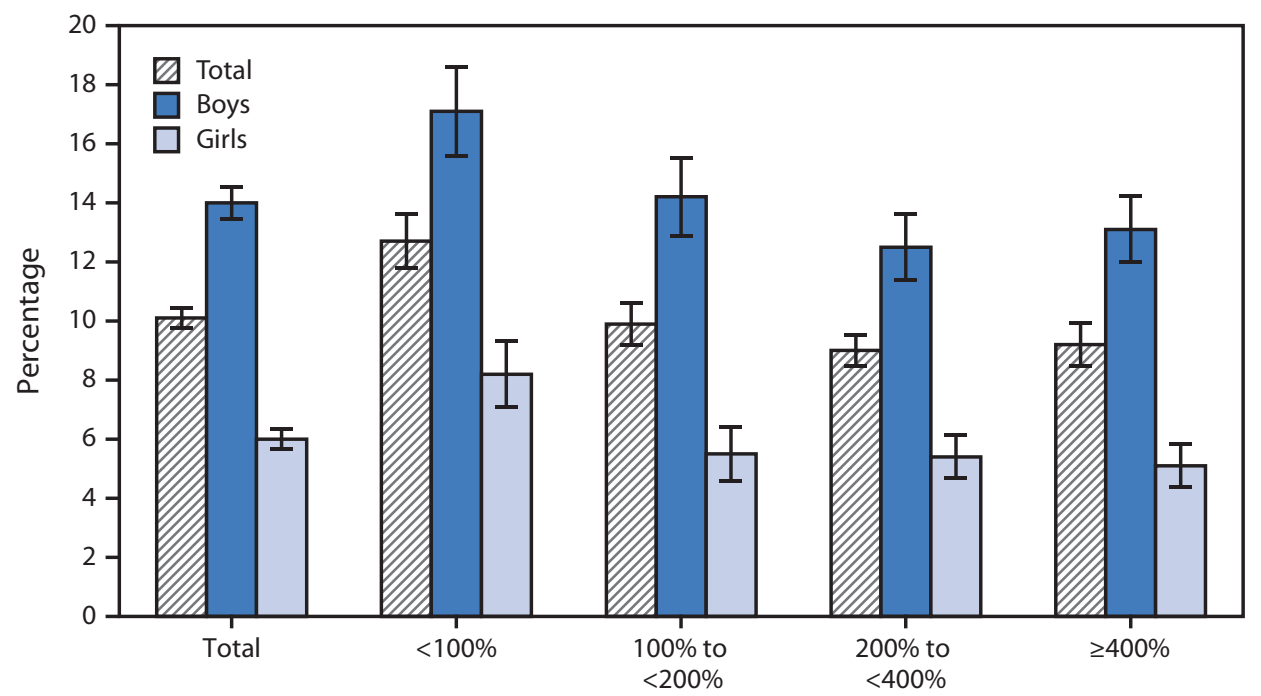

Family income as a percentage of poverty level

* With $95 \%$ confidence intervals indicated with error bars.

† Based on responses to the question, "Has a doctor or health professional ever told you that [child] had attention-deficit/hyperactivity disorder (ADHD) or attention deficit disorder (ADD)?"

$\S$ Poverty status is based on family income and family size using the annually updated U.S. Census Bureau poverty thresholds. Family income was imputed when missing.

" Estimates are based on household interviews of a sample of the noninstitutionalized U.S. civilian population and are derived from the National Health Interview Survey's sample child component.

During 2011-2014 approximately 10\% of all children aged 5-17 years were reported by parents to have been diagnosed with ADHD. The percentage of children who had ever been diagnosed with ADHD was significantly higher among boys (14\%) than among girls (6\%) overall and within each poverty status category. Among both boys and girls, poor children (i.e., those living in families with incomes $<100 \%$ of the poverty level) were more likely to have been diagnosed with ADHD than children living in families with incomes $\geq 400 \%$ of the poverty level.

Source: National Health Interview Survey. Available at http://www.cdc.gov/nchs/nhis.htm.

Reported by: Patricia Pastor, PhD, ppastor@cdc.gov, 301-458-4422; Cynthia Reuben, MA; Catherine Duran. 



The Morbidity and Mortality Weekly Report (MMWR) Series is prepared by the Centers for Disease Control and Prevention (CDC) and is available free of charge in electronic format. To receive an electronic copy each week, visit MMWR's free subscription page at http://www.cdc.gov/mmwr/mmwrsubscribe.html. Paper copy subscriptions are available through the Superintendent of Documents, U.S. Government Printing Office, Washington, DC 20402; telephone 202-512-1800.

Readers who have difficulty accessing this PDF file may access the HTML file at http://www.cdc.gov/mmwr/index2015.html. Address all inquiries about the MMWR Series, including material to be considered for publication, to Executive Editor, MMWR Series, Mailstop E-90, CDC, 1600 Clifton Rd., N.E., Atlanta, GA 30329-4027 or to mmwrq@cdc.gov.

All material in the MMWR Series is in the public domain and may be used and reprinted without permission; citation as to source, however, is appreciated. Use of trade names and commercial sources is for identification only and does not imply endorsement by the U.S. Department of Health and Human Services.

References to non-CDC sites on the Internet are provided as a service to $M M W R$ readers and do not constitute or imply endorsement of these organizations or their programs by CDC or the U.S. Department of Health and Human Services. CDC is not responsible for the content of these sites. URL addresses listed in $M M W R$ were current as of the date of publication.

ISSN: 0149-2195 (Print) 